\title{
The Stretch, Limit and Path Forward for Particle Rein- forced Metal Matrix Composites of 7075 Al-Alloys
}

\author{
Rupa Dasgupta \\ Advanced Materials \& Processes Research Institute [AMPRI], \\ CSIR, Bhopal, INDIA \\ E-mail: dasguptarupa@gmail.com \\ Received November 30, 2009; revised February 8, 2010; accepted February 12, 2010
}

\begin{abstract}
Al-based metal matrix composites [MMCs] have been the research interest of a wide spectrum of material scientists throughout the world for some over two decades now. The present paper has chosen one alloy system namely the 7xxx series and from an extensive literature review concluded that since the beginning of the new millennium nothing note worthy has been added to the knowledge already gained in the last quarter of the last century except confirm the earlier findings that MMCs if properly fabricated by choosing the processing route and with appropriate size and volume fraction of dispersoids can improve most of the mechanical, corrosion and wear resistant properties of the base alloy. The author's own research activities using this alloy system for making MMCs that include attempts to improve upon the properties by making composites, ageing and also secondary processing have been included. An attempt has been made to establish the stretch to which improvement is possible in the alloy system by making composites and trying all other routes known for meaningful improvement in properties. Further, the way forward for such particulate composites has been drawn to realise the material scientists' dream of seeing such MMCs as engineering components. For this, the areas which now need research include mass production of composites, focus on its machining, joining, processing as also reduction in the size of dispersoids are some of the areas that have been identified and discussed in the paper.
\end{abstract}

Keywords: Al-based MMCs, 7xxx Series, 7075 Alloy, Tempering, Ageing, Retrogression And Reageing, Hardness, Mechanical Properties, Wear Properties, Extrusion, Corrosion, Machining, Joining, Mass Production

\section{Introduction}

Material scientists and researchers in this area have been fulfilling the demand of the engineering sector in synthesizing materials to attain the demanded properties to enhance efficiency and cost savings in the manufacturing sector. In fulfilling this demand a certain trend has been followed, the materials presently been used is tried for improvement through known methods of alloy additions, heat treatment, grain modification and the like. Once the limit is reached through these methods either due to economic constraint or difficulty in mass production or further improvement is ruled out, does a different line of thought emerge in further improving the properties or decreasing cost and increasing efficiency. At times, a completely new system takes over, like was done around three decades back when due to the limits reached in alloy systems, metal matrix composites were thought of and after some two decades of experimental research the economically feasible routes, dispersoids and alloy system that can give meaningful improvement have been narrowed down. Alongside, basic understanding of mixing between the alloy and dispersoid has also now been reached. In the last decade though research continues in this field yet the results obtained were a mere confirmation of the previously attained results and a plateau in the improvement possible has been reached. But before the clogging takes place, it was essential to change the direction of research once again and it is only obvious that further improvement could be obtained in any system by adopting another route of fabrication. In this line secondary processing was the obvious choice, though much work has not been reported in this direction.

The present paper has made an attempt of finding the 
Table 1. Chemical composition limits of 7075 alloy.

\begin{tabular}{|c|c|c|c|c|c|c|c|c|c|c|}
\hline Weight & $\mathrm{Cu}$ & Mg & Mn & $\mathrm{Si}$ & $\mathbf{F e}$ & $\mathrm{Cr}$ & Zn & $\mathbf{T i}$ & \multicolumn{2}{|c|}{ Others } \\
\hline & & & & & & & & & Each & Total \\
\hline Minimum & 1.2 & 2.1 & - & - & - & 0.18 & 5.1 & - & - & - \\
\hline Maximum & 2.0 & 2.9 & 0.30 & 0.40 & 0.50 & 0.28 & 6.1 & 0.20 & 0.05 & 0.15 \\
\hline
\end{tabular}

limit of enhancing the mechanical and wear resistance properties of a commonly used Aluminium alloy, the 7075 alloy by different routs; by making (i) composites (ii) heat treatment of the alloy and composite and also (iii) extruding the alloy and composite to rods. A comparison in the properties attained by the different routes would help find the limit upto which the properties in this alloy system can be stretched. Further research in this area after this would not have anything much to add and this type of an activity to be used as a tool for 'stretching to the limit' any system before they see the light of the day as an engineering component.

\section{The Al-Zn-Cu-Mg Alloy System}

\subsection{Alloying Additions}

The main alloying element in the $7 \mathrm{XXX}$ series of Al-alloys is Zinc and is known for its high specific strength. In this series the 7075 alloy is the most commonly used by the engineering sector especially the aerospace industry. The chemical composition limit of 7075 alloy is as follows [1-4]:

The presence of $\mathrm{Mn}$ in the alloy is responsible for the uniform deformation through cross slip, for retarding fatigue damage accumulation and enhancing fatigue life.

The addition of $\mathrm{Cu}$ results in an increases in the stability of Guinier-Preston zones formed at room temperature together with a decreases in the nucleation temperature and also results in an increase in the strengthening ability and a lower sensitivity to the heating rate of ageing temperature, however, the higher super saturation of the $\mathrm{Cu}$ bearing alloy results in a higher quench higher sensitivity and at slow quench rates of the ternary alloy shows a higher strengthening potential. Again when the reinforcement particle size is decreased, tensile strength of the composite increases but fracture toughness follows the opposite trend-it increase as the particle size increases.

In addition to $\mathrm{Zn}, \mathrm{Mn}$ and $\mathrm{Cu}$ which are the two major constituents of the 7075 alloys, $\mathrm{Zr}$ is added. Its presence results in grain refinement and diffusion of $\mathrm{Cu}$ relatively quickly to grain boundaries and due to in consequence of non equilibrium segregation during quenching a solute depleted layer develops near the grain boundaries

\subsection{Phase Diagram and Phase Precipitation}

The phase diagram for the 7075 alloy is given in
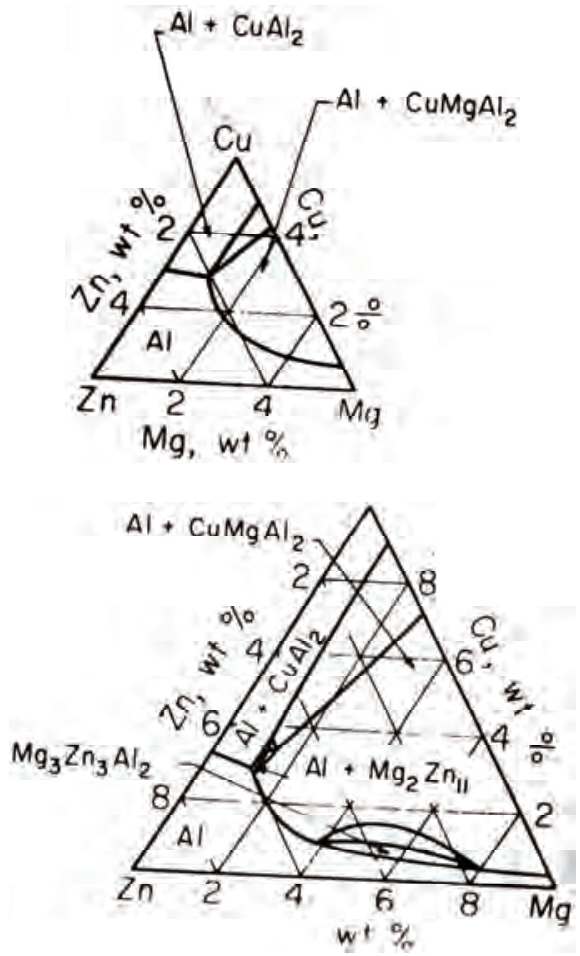

Figure 1. Phase diagram for the Al-Zn-Cu-Mg system.

\section{Figure 1 [1].}

The phase in equilibrium with an Aluminium matrix in commercial alloys are designated $\mathrm{MgZn}_{2}$ [M-Phase], $\mathrm{Mg}_{3} \mathrm{Zn}_{3} \mathrm{Al}_{2}$ [T-Phase] and $\mathrm{Mg}_{5} \mathrm{Al}_{3}$ [ $\beta$-Phase]. The first phase ranges in composition from $\mathrm{MgZn}_{2}$ to $\mathrm{Mg}_{4} \mathrm{Zn}_{7} \mathrm{Al}$. The T-Phase has a wide range of composition, from $74 \%$ Zinc-16\%Magnesium to 20\%Zinc-31\%Magnesium. The $\beta$-phase appears only when the magnesium content is considerably greater than the Zn content. Such alloys are strengthened primarily by $\mathrm{Mg}$ in solid solution. Precipitation hardening of alloys with $\mathrm{Zn}$ in excess of Mg occurs in the sequence zones through coherent precipitates to the M-Phase. Quaternary alloys contain copper, magnesium and zinc. The M-Phase composition ranges in the quaternary system from $\mathrm{MgZn}_{2}$ to $\mathrm{CuMgAl}$ and may be described as $\mathrm{Mg}[\mathrm{Al}, \mathrm{Cu}, \mathrm{Zn}]_{2}$. The range of composition for the T-Phase is from that of Al-Mg-Zn ternary to that of Phase designated $\mathrm{CuMg}_{4} \mathrm{Al}_{6}$ and may be described as $\mathrm{Mg}_{3}[\mathrm{Al}, \mathrm{Cu}, \mathrm{Zn}]_{5}$. A third phase is $\mathrm{CuMgAl}_{2}$ [S-Phase], with a small range of composition. The $\mathrm{CuAl}_{2}$ phase appears only if copper is considerably in excess of $\mathrm{Mg}$. Several nonequilibrium invariant melting reactions are encountered in the high strength quaternary alloys. A 
reaction at $475^{\circ} \mathrm{C}$ involving $\mathrm{M}, \mathrm{T}$, and S phases is usually encountered, but as copper content increases melting may be encountered down to $460^{\circ} \mathrm{C}$. Usually the J-Phase has the highest solvus temperature and is slow to dissapear during ingot homogenization. Precipitation hardening in high strength alloys is by the sequence leading to M-Phase. Zones and coherent precipitates are low in copper content and precipitates increase in copper content in the overageing regime. Additions of iron, manganese and silicon interact with one another and with copper and magnesium. Chromium reacts with aluminium and magnesium to form a dispersoid.

The ageing of rapidly quenched $\mathrm{Al}-\mathrm{Zn}-\mathrm{Mg}$ alloys [5-10] from room temperature to relatively low ageing temperatures is accompanied by the generation of GP zones having an approximately spherical shape. With increasing ageing time, GP zones increase in size and the strength of the alloy increases. Extended ageing at temperatures above room temperature transforms the GP zones in alloys with relatively high $\mathrm{Zn}-\mathrm{Mg}$ ratios into the transition precipitate known as $\eta^{\prime}$ or $\mathbf{M}^{\prime}$, the precursor of the equilibrium $\mathrm{MgZn}_{2}, \eta$ or $\mathrm{M}$ phase precipitate. Ageing time and temperatures that develop the highest strength characteristics of the T6 temper produce zones to have an average diameter of 2 to $3.5 \mathrm{~nm}$.

The addition of higher copper contents affords greater precipitation hardening, with some contribution of $\mathrm{Cu}$ atoms to zone formation. Crystallographic arguments indicate that copper and aluminium atoms substitute for zinc in the $\mathrm{MgZn}_{2}$ transition and the phase $\mathrm{MgZn}_{2}$ and $\mathrm{MgAlCu}$ form an isomorphous series in which an aluminium atom and a copper atom substitutes for two $\mathrm{Zn}$ atoms. Electropotential measurement and X-ray analysis indicate that copper atoms enter into the $\eta^{\prime}$ phase during ageing temperatures above about $150^{\circ} \mathrm{C}\left[300^{\circ} \mathrm{F}\right]$, thus ageing these alloys above this temperature substantially increase their resistance to stress corrosion cracking.

In cast ingot form, alloy 7075 forms one or more variants of $[\mathrm{Fe}, \mathrm{Cr}]_{3} \mathrm{SiAl}_{12}, \mathrm{Mg}_{2} \mathrm{Si}$ and a psuedobinary eutectic made up of $\mathrm{Al}$ and $\mathrm{MgZn}_{2}$. The latter phase contains $\mathrm{Al}+\mathrm{Cu}$ as a substitute for $\mathrm{Zn}$ and can be written as $\mathrm{Mg}[\mathrm{Zn}, \mathrm{Cu}, \mathrm{Al}]_{2}$. Subsequent heating causes the iron rich phases to transform to $\mathrm{Al}_{7} \mathrm{Cu}_{2} \mathrm{Fe}$. $\mathrm{Mg}_{2} \mathrm{Si}$ is relatively insoluble and tends to somewhat spheroidize, $\mathrm{Mg}[\mathrm{Zn}, \mathrm{Cu}, \mathrm{Al}]_{2}$ rapidly begins to dissolve and at the same time some $\mathrm{Al}_{2} \mathrm{CuMg}$ precipitates also dissolve as this phase requires high temperature and lengthy soaking to completely dissolve. $\mathrm{Cr}$ is precipitated from super saturated solution as $\mathrm{Cr}_{2} \mathrm{Mg}_{3} \mathrm{Al}_{18}$ dispersoid concentrated heavily in the primary dendrite regions. A well solutionized wrought alloy contains only $\mathrm{Al}_{7} \mathrm{Cu}_{2} \mathrm{Fe}$, $[\mathrm{Fe}, \mathrm{Cr}]_{3} \mathrm{SiAl}_{12}$ and $\mathrm{Mg}_{2} \mathrm{Si}$, along with the dispersoid. Recrystallized grains are extremely elongated or flattened because of dispersoid bonding and unrecrystallized regions are not unusual even in sheet. The unrecrystal- lized regions are made up of very fine subgrains in which boundaries are decorated by hardening precipitate.

\subsection{Ageing Behaviour}

The 7075 alloys are used both in the un-tempered condition and tempered condition corresponding to T6 and T7 tempering [5-10]. T6 tempering is done by solution heat treatment at $466^{\circ} \mathrm{C}$ to $482^{\circ} \mathrm{C}$ followed by water quenching followed and ageing at between $115^{\circ} \mathrm{C}$ to $130^{\circ} \mathrm{C}$ for obtaining high strength in reasonably short ageing cycle. An alternate tempering known as T7 or RRA [Retrogression and Reageing] technique is also used which is a two stage treatment after T6 tempering; the samples are retrogressed at $200^{\circ} \mathrm{C}$ for duration short enough to allow only dissolution of precipitates. The second stage involves reageing i.e. the retrogressed samples were reaged at $120^{\circ} \mathrm{C}$ to fully restore the peak aged condition of the T6 temper. In the RRA treatment the maximum static tensile and compressive properties of $\mathrm{T} 6$ temper are combined with the resistance to stress corrosion of the T73 temper. RRA treatment results in precipitate dissolution and then re-precipitation growth of coarser equilibrium phase particles in the grain boundary regions. For short time retrogression, the hardness can be restored after reageing but almost no restoration is observed for prolonged retrogression time [ $>50 \mathrm{~min}]$. RRA is effective only for alloys containing coherent dispersoids but is less effective for alloys containing incoherent dispersoids. The RRA process improves the resistance of stress corrosion cracking in high strength 7xxx alloys which have the same strength of T6 temper [11-13]. The TMT process improved strength, fracture toughness, fatigue property and corrosion resistance. Also stability in property, higher strength, improved corrosion resistance and lower rate of growth of fatigue cracks are obtained by the use of elevated temperature ageing. TEM studies have shown that 75 min retrogressed 7075-T6 $\mathrm{Al}$ alloy has smaller grain boundary precipitated and a higher dislocation concentration than the T6 stage. The optimum retrogression time changes with material thickness.

\subsection{Properties of Alloys}

Density is reduced by addition of magnesium and increased by all other element. For commercial alloys it ranges between $2.740 \mathrm{~kg} / \mathrm{m}^{3}$ and $2.830 \mathrm{~kg} / \mathrm{m}^{3}$, with most alloys around $2.800 \mathrm{~kg} / \mathrm{m}^{3}$ [1].

The mechanical properties of the cast and aged alloys are shown in Table 2 [1-4,14].

These alloys achieve their strength by precipitation through a complex sequence of Guinier Preston [GP] zones, $\eta$ ' nucleating on GP zones, $\eta^{\prime}$ transforming into $\eta$. In addition their processing route is rather complex, including some plastic strain followed by natural ageing 
Table 2. Tensile properties of 7075 alloy.

\begin{tabular}{cccc}
\hline Property & As cast & Naturally Aged & Artificially Aged \\
\hline Hardness [HV] & $500-700$ & $500-800$ & $800-1200$ \\
UTS [MPa] & $100-150$ & $150-200$ & $180-250$ \\
YS [MPa] & $50-100$ & $80-150$ & $120-200$ \\
Elongation [\%] & $1-3$ & $2-5$ & $0-2$ \\
Shear strength [MPa] & $152 \mathrm{MPa}$ & $331 \mathrm{MPa}$ & $317 \mathrm{MPa}$ \\
Poisson Ratio & & 0.33 at $20^{\circ} \mathrm{C}\left[68^{\circ} \mathrm{F}\right]$ & \\
Elastic Modulus [GPa] & Shear : 26.9 & Tension: 71.0 & $159 \mathrm{MPa}[23 \mathrm{Ksi}]$ at $5 \times 10^{8}$ cycles \\
Fatigue Strength [MPa] & & 152.4 \\
\hline
\end{tabular}

and a multistep artificial ageing treatment. In these alloys zinc is the major constituent.

The 7XXX alloys are typically used for aircraft structural parts and other highly stressed applications where very high strength and good resistance to corrosion is required. These alloys are widely used in aeronautics industry and aerospace structural applications

\subsection{Property Improvement through Mechanical Processing}

The alloy system has been moderately subjected to different types of secondary processing. The following observations have been reported on secondary processed alloys of this series:

- The grain structure of the rolled plate [15-16] was found to be comprised of high aspect ratio grains elongated in the rolling direction of the plate. The structure consisted largely of unrecrystallized material although a small volume fraction of recrystallized grain was present. The elongated grains contained an internal structure of small [1 to $5 \mu \mathrm{m}$ ] equiaxed subgrain with an average misorientation across subgrain boundaries $\sim 5$ deg.

- The microstructure of a forged product which is characterized by 'pan cake' unrecrystalized grain morphology [17]. Observation of unetched section revealed the presence of constituent phases with particle sizes up to $20 \mu \mathrm{m}$. The major constituent phase was present as fragmented rounded gray coloured particles strung out into longitudinal direction. Qualitative energy dispersive $\mathrm{x}$-ray analysis of these particle identified them as $\mathrm{Al}, \mathrm{Cu}$, and Fe reached. Upon etching in Keller's reagent, these particles turned light brown conforming their identification as $\beta$ [AlCuFe].

- The grains of the 7475 alloy formed sheet were longer, approx. $11.5 \mu \mathrm{m}$ than in the as received sheet, approx $9.5 \mu \mathrm{m}$ [18]. Addition the original grain had pan cake shape, whereas the grain in the form parts appeared to be more equiaxed.

- Forming pressure corresponding to optimum super plastic condition and low back pressure result in a more uniform thickness distribution in the formed part. The average size of the originally non equiaxed grain increases 20\% during initial training. Grains become more equiaxed with increasing strain while maintaining nearly constant grain size for strain in the range 1-1.4 [19].

- The compressive stress-strain response of as cast and aged 7075 alloys is found to depend strongly on both the applied strain rate and the test temperature. However, the aged material is generally found to be stronger than the as cast material. The work hardening rate is seen to decrease with increasing strain, stain rate and temperature and its value is higher in the aged material than in the as cast material [20].

\section{AMMCs of the Series}

\subsection{From the Beginning, Since 1980s}

Literature review of Al-Zn based composites show that this system has been widely investigated both in terms of understanding the mechanism of formation and property evaluation of composites [21-53]. Different routes for preparation of composite have been adopted, however for practical purposes the casting, powder and squeeze casting routes have been adopted and in some cases these have been subjected to secondary processing i.e. extrusion of as cast composite and consolidation followed by extrusion for composite prepared by powder metallurgy ones. Properties have been characterized for cast and aged composite.

The main dispersoid that have been investigated are $\mathrm{SiC}$ and $\mathrm{Al}_{2} \mathrm{O}_{3}$. Stronger matrix alloys tend to produce stronger composites although the increase in strength due to reinforcement tends to be lower when higher strength matrix alloy are used and in the case of matrix alloys with less strength reinforcement has been observed to lead to reduction in strength; it was found that composites containing $13 \mu \mathrm{m}$ particles possesses greater toughness than those containing $5 \mu \mathrm{m}$ particles.

The excellent flow resistance and ductility of $\mathrm{Al} 7 \mathrm{xxx}$ series alloys is achieved through the formation of extremely small, uniformly dispersed particles of a second phase within the original aluminium phase matrix, i.e. ageing process. The enhancement in strength is highly dependent on the type, distribution and size of precipitate particles present.

The microstructural studies of composite in the cast 
Table 3. Best mechanical properties attained by MMCs of 7xxx alloy system.

\begin{tabular}{|c|c|c|c|c|c|c|}
\hline $\begin{array}{c}\text { Dispersoid } \\
\text { [Vol.\%] }\end{array}$ & $\begin{array}{c}\begin{array}{c}\text { Method of Forma- } \\
\text { tion }\end{array} \\
\end{array}$ & $\begin{array}{c}\text { Ageing Condi- } \\
\text { tion }\end{array}$ & Hardness [HV] & UTS [MPa] & $\begin{array}{c}\text { Reduction in Area } \\
{[\%]}\end{array}$ & $0.2 \%$ Proof Stress \\
\hline $\begin{array}{l}\mathrm{SiC}[15 \%] \\
\quad[5 \mu \mathrm{m}]\end{array}$ & Spray deposited & $\begin{array}{l}\text { Under aged } \\
\text { Peak aged } \\
\text { Over aged }\end{array}$ & -- & $\begin{array}{l}630 \\
574\end{array}$ & $\begin{array}{c}10 \\
12.5\end{array}$ & $\begin{array}{l}570 \\
510\end{array}$ \\
\hline $\mathrm{SiC}[15 \%][13 \mu \mathrm{m}]$ & Spray deposited & $\begin{array}{l}\text { Under aged } \\
\text { Peak aged } \\
\text { Over aged }\end{array}$ & $\begin{array}{l}-- \\
-- \\
--\end{array}$ & $\begin{array}{l}645 \\
496 \\
453\end{array}$ & $\begin{array}{c}4.8 \\
5 \\
1.3\end{array}$ & $\begin{array}{l}595 \\
539 \\
431\end{array}$ \\
\hline $\operatorname{SiC}[15 \%][60 \mu \mathrm{m}]$ & Spray deposited & $\begin{array}{l}\text { Under aged } \\
\text { Peak aged } \\
\text { Over aged }\end{array}$ & $\begin{array}{l}-- \\
-\end{array}$ & $\begin{array}{l}504 \\
493\end{array}$ & $\begin{array}{l}1 \\
2\end{array}$ & $\begin{array}{l}501 \\
484\end{array}$ \\
\hline $\begin{array}{c}\mathrm{SiC}[15 \%][2-3 \\
\mu \mathrm{m}]\end{array}$ & $\begin{array}{c}{[\text { forming }} \\
\text { temp/press] } \\
{[499 / 2.07]} \\
{[5.4 / 2.07]} \\
{[529 / 2.07]}\end{array}$ & -- & -- & $\begin{array}{l}455 \\
448 \\
420\end{array}$ & -- & $\begin{array}{l}373 \\
368 \\
332\end{array}$ \\
\hline $\mathrm{SiC}[5 \%][2-3 \mu \mathrm{m}]$ & $\begin{array}{l}{[490 / 2.07]} \\
{[505 / 2.07]} \\
{[520 / 2.07]}\end{array}$ & -- & -- & $\begin{array}{l}448 \\
463 \\
432\end{array}$ & -- & $\begin{array}{l}391 \\
395 \\
330\end{array}$ \\
\hline
\end{tabular}

condition have been widely investigated. The microstructure is dependent on a number of parameters like macro segregation of dispersoid, primary and secondary dendrite spacing, solidification rate, solidification time, dendrite ripening; the cast structure exhibits coarse dendrite grains, however in contrast small non dendritic structure was observed in the aged structure. In both materials the grain size decreases as the strain rate increases.

The tensile properties of the composite have been investigated by several investigators with a view to assessing its properties vis-à-vis conventional alloy to find commercial application of the composite. Properties have been evaluated in cast, aged and processed conditions for composites prepared by different route. The main observations are: 1) addition of 5 and $13 \mu \mathrm{m}$ particles in 7075 alloy increased the $0.2 \%$ proof stress and UTS values in composites made by spray deposition over the monolithic material. The addition of $60 \mu \mathrm{m}$ particle however, reduced the $0.2 \%$ proof stress and UTS of the resulting composite in the under aged stress and UTS of the resulting composites in the under aged and peak aged condition. There are only small differences in the $0.2 \%$ proof stress and UTS of 5 and $13 \mu \mathrm{m} \mathrm{SiC} \mathrm{particulates} \mathrm{rein-}$ forced composite but $60 \mu \mathrm{m}$ particulate reinforced material has much lower yield and fracture strength. 2) It has been reported that the $0.2 \%$ proof stress and tensile strength tends to increase and toughness and ductility decreases with increasing volume fraction. For a constant volume fraction of reinforcement tensile properties generally tend to increase with a decrease in particle size for a larger particle composite ductility is reduced compared with that of monolithic material. 3) The yield strength $[0.2 \%$ offset $]$ and ultimate tensile strength increased only marginally with an increase in strain rate. Increase in tensile strength is accompanied by decrease in tensile ductility. 4) Environment was found to have little influence on yield strain of the high purity alloy. However, strength increases only marginally with an increase in strain rate.

Literature on secondary processing of composites of this series of alloys is limited although extensive reports are available on the secondary processing of alloys of $7 \mathrm{xxx}$ series. However, these observations are not been detailed in this paper since it deals with composites only. Some studies have been carried out on the effect of alloying elements in secondary processing of this composite system; it mentions that the presence of iron produces a slight decrease in strength, elongation and fracture in wrought product. Iron together with manganese may produce a slight increase in strength with limited increase in elongation. Manganese, chromium, molybdenum and zirconium appear to have a strong strengthening effect with corresponding decrease in \% elongation. The effect of silicon addition varies some what depending on Mg: Zn ratio [54,55]. The properties attained by investigators adopting different processing routes for making composites are given in Table 3 below:

Since this series of alloys are not generally used for wear resistant purposes there is no report on the wear properties of composites prepared from this series of alloys. However there is a study in which the wear behaviour of high tensile strength aluminium alloys under dry and lubricated conditions for 7004-T6 alloys were compared with 2014 alloys. It has been observed that these alloys are easily worn out. Severe wear at high contact load have been reported. In paraffin oil, the wear rates were approx 1/10 the wear rates under dry condi- 
tions 7004-T6 showed a lower friction coefficient compared to 2024-T4. For 7004-T6, wear cracks which would propagate in the sliding direction occurred and large and elongated particles were detected [48-53].

Creep resistance of the alloys and composites both are relatively low, however longer creep life can be achieved if the load is intermittently relieved and the material is allowed a period of rest. Residual stresses from working processes may reduce creep resistance and so does precipitation during creep [56-58].

\subsection{The Recent Past [Since 2000]}

The recent past has not since much progress in the research of this series of composites. The researchers have more or less confirmed the findings of earlier researchers and at times provided an understanding of the behaviour observed. The role of work hardening characteristics of matrix alloys in the strengthening of metal matrix composites has been shown to be associated with a high dislocation density in the matrix due to the difference in coefficient of thermal expansion between the reinforcement and the matrix. In a study where the composites were made by a pressureless infiltration method, the composite reinforced with $\mathrm{SiC}$ particles exhibited higher strength values than the control alloy in all aging conditions (underaged (UA), peak-aged (PA), and overaged (OA)), as well as a solution treated condition. Spontaneous infiltration was further prompted owing to the combined effect of both $\mathrm{Mg}$ and $\mathrm{Zn}$. This may lead to an enhancement of wetting between the molten alloy and the reinforcement. Consequently, strength improvement in a composite may be attributed to good bond strength via enhancement of wetting. The grain size of the control alloy is greatly decreased to about $2.5 \mathrm{~mm}$ compared to $10 \mathrm{~mm}$ for the commercial alloy. In addition, the grain size in the composite is further decreased to about $2 \mathrm{~mm}$. These grain refinements contributed to strengthening of the control alloy and the composite [59]. In another recent study, the role of work hardening characteristics has been shown to be due to increased prismatic punching of dislocations. This relationship of decreasing work hardening rate associated with increasing prismatic punching of dislocations for different Al-based matrices is in the order 7075, 2014, 7010, 2024, 6061 and commercial purity aluminium leading to increased strength increments has been noted. From the study, it is concluded that lower the work hardening rate, higher is the strengthening and vice versa in particulate metal-matrix composites [60]. The corrosion behaviour of the MMCs was studied by electrochemical measurements to study the effect of the addition of silicon carbide on the corrosion behaviour of the MMC [61]. The electrochemical noise result shows that the amplitude of the potential noise of the composite is lower than that of the spray deposited 7075 alloy. The potentiodynamic polari- zation curves results show that both the cathodic oxygen reduction current density and the anodic dissolution current density of the 7075/SiCp MMC are less than those of the 7075 alloy. Thus, the addition of $\mathrm{SiC}$ particles increases the corrosion resistance of the MMC. This may be due to that the microstructure of the spray deposited MMC is compact and SiC particles are nonmetallic material, the addition of it minimizes the real corrosion area of the alloy. In another study [62], an attempt has been made to fabricate $\mathrm{Al}-\mathrm{SiC}_{\mathrm{p}}$ and $\mathrm{Al}-\mathrm{Al}_{2} \mathrm{O}_{3}$ composite materials by powder metallurgy technique at different volume percentage of reinforcement $(5,10,15,20$, and 25\%). The corrosion behavior of the composites was analyzed using AC Gill potentiostat with $3.5 \mathrm{wt} \% \mathrm{NaCl}$ medium. Four factors, five level, central composite, rotatable design matrix is used to optimize the required number of experiments. The mathematical models were developed by the response surface method (RSM). The developed models have been checked for their adequacy and significance by the $F$-test and $t$-test, respectively. The results obtained from the mathematical models have been optimized and also tested using conformity test runs that closely match the experimental results. A mathematical model has been successfully developed [63] to predict the wear rate of AA7075 aluminium/SiCp composite material fabricated by powder metallurgy technique at 95\% confidence level within range of investigation based on the results obtained after studying the effect of reinforcement particle size, applied load and sliding speed on the dry sliding wear behaviour of AA7075 aluminium/SiCp composites fabricated by powder metallurgy technique with 5-25 vol.\% SiCp with an average particle size of about $40-150 \mu \mathrm{m}$ using the conventional powder metallurgy $(P / M)$ process. The effect of selected process variables on the porosity of $7075 \mathrm{Al}$ alloy $10 \% \mathrm{SiC}$ composite and subsequent optimal settings of the variables have been obtained using Taguchi method [64]. The results indicate that the holding time, holding temperature and stirring speed are the significant variables. Stirring time is insignificant variable. As the holding time, holding temperature and stirring time increases the porosity decreases. When the stirring speed increases, porosity increases. The predicted optimal value of porosity is $4.71 \%$.

Although very limited studies have been reported on processing of composites, a particular study reports in detail the effect of extrusion and rolling on a $\mathrm{SiC}_{\mathrm{p}} / 7075$ aluminum alloy composite fabricated by squeeze casting using a vortex method [65]. The composites were hot rolled to the total rolling reduction of about $94 \%$ at temperatures between $573 \mathrm{~K}$ and $773 \mathrm{~K}$ and at a rolling strain per pass of 0.10 . Superplastic characteristics such as microstructure and apparent activation energy were compared with these of the composites made by other processes in order to clarify the superplastic deformation mechanism. Fine grain size of about $1 \mu \mathrm{m}$ was attained 
in the composite rolled at a temperature of $573 \mathrm{~K}$ and at the strain per pass of 0.1 . In the case of rolling at $573 \mathrm{~K}$, the composite obtained exhibited high strain rate superplasticity with a maximum elongation of about $230 \%$ at strain rate of $7 \times 10^{-1} \mathrm{~s} 1$ and at $798 \mathrm{~K}$. Plots between $\varepsilon^{1}$ and $\sigma$ showed linear relation when exponent of $n=2$ was assumed. Threshold stresses obtained from the linear relations were largely dependent on the testing temperature. Apparent activation energy determined from relationship between strain rate and testing temperatures was $244 \mathrm{~kJ} / \mathrm{mol}$, which was smaller than that for the powder metallurgical and mechanically alloyed Aluminium composite. It seems that there is no substantial difference of high strain rate superplastic mechanism between the composite fabricated by a vortex method and powder metallurgical aluminum alloy composites.

\subsection{What Has Seldom Been Tried}

Inspite of the enormous amount of R\&D that has gone into Al-based MMCs of every possible alloy with different dispersoids establishing beyond doubt the usefulness of making composites that can be competitive on a production scale to Al-alloys and steels in some cases, and although some of these have already been in commercial use now, a few areas still remained to be explored. These areas have seldom been researched on or reported in the literature though all researchers would agree that these areas needs to be addressed to before Al-base composites are freely available in the market as an alternative to commercial alloys for engineering applications. The areas in which very little or no work has been done/reported include the following:

- Machining of Composites: Particulate MMCs are invariably harder than the base alloy and more abrasive due to the incorporation of the second phase. Hence machining of these poses difficulty as tools used for Al-based alloys are generally used even for the MMCs; the tools wear out fast and needs frequent replacement that adds to the cost of processing of these materials. Most of the times when conventional tools used for $\mathrm{Al}$ do not work properly or are blunted tools for machining harder materials like diamond tip tools are used which are costly. But a systematic study has not been done in trying to fabricate/design tools especially for MMCs.

- Joining of Composites: This aspect has not at all been reported though it is a very important area as making components will require joining of two pieces quite frequently. Welding could be the most apt method of joining but welding rods for the purpose needs to be developed. The other known methods of joining similar and dissimilar metals needs to be assessed and researched on.

- Primary/Secondary Processing: The literature available on primary processing including forging, extrusion and rolling is very limited and scanty. Most of the work is on extrusion of only MMCs made from powder met- allurgy route in which small samples have been extruded. But before thinking of engineering applications for MMCs, the difficulties in processing these materials needs to be addressed to and parameters optimised. The present paper reports some of the authors' experience in this field.

- Equi Channel Angular Pressing: Equi Channel Angular Pressing [ECAP] is emerging as a competitive route of processing Al-based alloys wherein the grain size is drastically decreased by passing billets through a die containing two channels, equal in cross section, intersecting at a certain angle introducing large shear strain without any reduction in the cross section of the material. Since the process is applicable to large samples, it appears to have the potential for significantly changing the material properties by effective grain size reduction even in a bulk form. This area has never been reported to have been tried for MMCs. It is felt that Al-based MMCs will respond positively to ECAP adding to the benefits of composite making.

- Ultrafine Dispersoids: Dispersoid size, shape, volume fraction, wettability and distribution play the most important role in the properties attained in MMCs. A lot of research has centered on optimizing these parameters and based on the results property designing of composites is possible. However, all the experimentation has stopped at decreasing the dispersoid level below $10 \mu \mathrm{m}$, possibly due to the difficulty in dispersing uniformly and without coagulation finer particles in the matrix especially when the liquid metallurgy route is adopted for making the composites. If the coagulation problem cannot be addressed on decreasing the particle size below $10 \mu \mathrm{m}$, alternate methods of fabrication have to be attempted at like in-situ composites, which has been a modern trend of research for making MMCs. Again, in the present age of nano materials methods of dispersion or making composites with nano sized dispersoids holds a lot of potential for commercial exploitation in the future.

- Bulk Production: One of the causes could be the most important cause as to why Al-based MMCs inspite of all its advantages are yet to see the light of the day extensively as engineering components is the level of production. Researchers are content with the high quality yet small quantities that they can repetitively produce in their laboratories, but the engineering sector is not convinced that the same benefits can be replicated on up scaling. Either party is not ready to bridge the gap by producing the material in bulk due to a number of reasons different for either party. But unless the fear in the mind of the users is removed as to the property improvement even when produced in bulk quantity by the researchers, their dream to see their research product in the market will be difficult to realise. So also, the manufacturing units should be entrepreneurial enough to take some risk in this matter, as certain changes might be 
needed in their production line up when alloys are replaced by composites. Somewhere by some groups are needed to take up the challenge of bridging the gap if Al-MMCs are to see the light of the day in the near future.

\section{Our Results}

The present paper has made an attempt of finding the limit of enhancing the mechanical and wear resistance properties of a commonly used Aluminium alloy, the 7075 alloy by different routs; by making 1) composites 2) heat treatment of the alloy and composite and also 3) extruding the alloy and composite to rods. A comparison in the properties attained by the different routes would help find the limit upto which the properties in this alloy system can be stretched. The experimental setups and results obtained are detailed below.

\subsection{Experimental Details}

\subsubsection{Making of Alloy and Composite}

The Al-based alloy confirming to the 7075 composition with $1.6 \mathrm{Cu}, 2.5 \mathrm{Mg}, 5.6 \mathrm{Zn}, 0.3 \mathrm{Cr}$ was selected for the present study. The chemical composition of the alloy was analysed using SPARKMET optical spectrometer [Model: SPECTRA] for confirmation.

For preparing composites from these alloys; 10 volume \% of dispersoids of $\mathrm{SiC}$ of were used with size between 20-40 $\mu \mathrm{m}$. The composites were prepared by the liquid metallurgy technique. For preparing the composites, the alloys were melted in a gas fired furnace in a graphite crucible. The melted alloy was fluxed with Coveral 11 and degassed with dry nitrogen gas. The pre weighed quantity and preheated dispersoids were poured into the melt after passing through a sieve. During insertion of the dispersoid the melt was stirred constantly by means of a stirrer placed in the melt operated by a motor. The stirrer speed was controlled as required. After complete insertion of the dispersoids in the molten alloy, the alloy was simultaneously stirred and heated for some time for uniform mixing and temperature. The melt with the dispersoids were then poured into preheated permanent moulds of required size and shape.

\subsubsection{Ageing and Tempering}

The alloys and composites were aged under T6 tempering and adopting retrogression and re-ageing method [RRA]. In the RRA method, the samples were quenched and aged as per the following steps:

- The alloys and composites were aged at $490^{\circ} \mathrm{C}$ for 8 hours and water quenched. The quenched samples were heat treated at $120^{\circ} \mathrm{C}$ for 24 hours and were furnace cooled. This corresponds to T6 ageing.

- The T6 aged samples were retrogressed at $200^{\circ} \mathrm{C}$ for 45 minutes.
- The retrogressed samples were re-aged at $120^{\circ} \mathrm{C}$ for 24 hours.

\subsubsection{Extrusion}

A 400 tonne hydraulic press with extrusion facility was used for extrusion experimentation. The alloy and composites were sized to a diameter of $50 \mathrm{~mm}$ diameter and $60 \mathrm{~mm}$ length for extrusion to rods at an extrusion ratio of 10:1. The billets were homogenised under at $480^{\circ} \mathrm{C}$ for 12 hours. A pressing speed of $0.4 \mathrm{~mm} / \mathrm{sec}$ was used and billets were soaked at $350^{\circ} \mathrm{C}$ for two hours before extrusion. The container, liner and billet were maintained at the extrusion temperature by externally heating the complete setup, to prevent heat loss during extrusion. The pressure required for successful extrusion was compared for optimizing the extrusion process.

\subsubsection{Laboratory Tests}

For microstructural studies, samples from the cast and aged alloys and composites of size approximately $20 \mathrm{~mm}$ diameters were metallographically polished and etched in Kellar's reagent. The microstructure of the sample was observed in the optical microscope at lower magnifications upto X500 and in the JEOL scanning electron microscope operating at $20 \mathrm{KV}$ at higher magnifications for a better understanding of the constituent phases in the microstructures. The secondary mode of electron emission was initially used for the microstructural investigations. However, when the precipitates expected to be precipitated at the grain boundaries was not properly visible with this mode, the back scattered electron emission mode of the scanning electron microscope was used for observing the precipitation of phases.

Bulk hardness was determined using the EQUOTIP SN 716-1159, Vers-1.16 hardness tester in which the indentation was produced using the Tungsten carbide ball indenter of $20 \mathrm{~mm}$ diameter with a test tip of $3 \mathrm{~mm}$ diameter.

The tensile properties i.e. ultimate tensile strength [UTS] and \% elongation were determined in the Shimadzu make Universal Testing Machine [UTM] of capacity 100 tonne. Tests were carried out at a load of 4 tonne with load increment of 0.4 tonne. Fractographic analysis of the fractured tensile samples was carried out in which the fractured surface was observed in the scanning electron microscope in order to understand the mechanism of material failure and changes in the mode of failure, if any, as a result of adding particulates to the alloy and extruding them.

The specimens were subjected to dry sliding wear tests under dry conditions using a pin-on-disc wear testing [Figure] [Cameron Plint make]. The test specimen in this case were in the form of cylindrical pins of length $53 \mathrm{~mm}$ and $8 \mathrm{~mm}$ in diameter and the disc counterpart was of AISI 304 grade stainless steel [Fe 0.08-C 2.0-Mn 1.0- Si 8.0-Ni $18.0 \mathrm{Cr}$ ] having a hardness of $194 \mathrm{HV}$. The specimen was held against the rotating steel disc and this 
sliding motion results in wear of the pin. The weight of the specimen was taken after every $500 \mathrm{~m}$, sliding distance. The weight loss was calculated from the difference in weight between the initial weight and weight after a specified number of rotations. Dividing the weight loss by the density of the material [calculated by Archimedes principle] gives the volume loss. This volume loss was taken for comparing the wear behaviour. Further, the wear rate was calculated by dividing the volume loss by the total distance traversed. Experiments were conducted in the present study at two speeds of rotation, one low at $200 \mathrm{rpm}$ and the other high at $750 \mathrm{rpm}$ corresponding to linear speeds of $1.04 \mathrm{~m} / \mathrm{s}$ and $3.92 \mathrm{~m} / \mathrm{s}$ respectively. Tests were carried out under three applied pressures, i.e. 1,3 and $5 \mathrm{MPa}$; wear loss was measured at distance corresponding to a sliding distance of $2500 \mathrm{~m}$ at intervals of $500 \mathrm{~m}$ and the corresponding volume loss calculated. Temperature rise of the specimen was not noted under the present study. The worn surface was studied under the scanning electron microscope [SEM] to study the nature of material removal and surface damage and to compare between material removal mechanism between the cast, aged and extruded conditions and between the alloy and composites under identical conditions.

\subsection{Results and Discussion}

\subsubsection{Microstructural Observations}

The microstructure of the cast, aged under T6 and RRA conditions and extruded rods for the alloy and composite is shown in Figure 2.

In the as cast state, the 7075 alloy shows heterogeneous precipitation along the grain boundaries as well as inside the grain boundaries [Figure 2(a)]. The alloy exhibits a black filigree of MgZn [18]. Under T6 conditions, there is heavy precipitation in the grains although the grain boundaries are not very clearly defined [Figure 2(b)], and under RRA conditions dissolution of grain boundaries was observed [Figure 2(c)] and shows a granular structure with grains of varying size and distribution of very fine phases in the grains in the Al-matrix resulting from non uniform solidification rates during casting [Figure 2(a)]. On extrusion directionality is seen along the longitudinal direction and the grain structure is completely broken down [Figure 2(d)]. The transverse section exhibits a granular structure [Figure 2(e)] but the phases are not much resolved. The cast composite exhibits [Figure 2(f)] a near uniform distribution of the particulates within the matrix and clear dendrites are seen in the matrix of Aluminium; grain boundaries are clearly defined with some precipitates in the grains. On ageing the 7075 composite, dissolution of grain boundaries was observed together with coagulation of precipitates around the $\mathrm{SiC}$ dispersoids [Figure 2(g)]. Again on extrusion directionality [Figure 2(h)] is seen and distribution of particulates uniformly is also observed. In the transverse section of the extruded composite, studs of the particle heads can be seen uniformly distributed in the matrix [Figure 2(i)]. A few particles [dispersoids] are seen to have been conglomerated in the extruded condition.

\subsubsection{Hardness}

The bulk hardness [HB] was measured on at least ten locations on the polished and etched sample and the average of the values with standard deviation are tabulated in Table 4.

It is seen from the above table that making composites drastically increases the hardness of the alloy by nearly $40 \%$ and extruding them further increases the value by some 25\% [Table 2]; the latter improvement is due to strain induced strengthening during the processes involved.

\subsubsection{Tensile Properties and Fractographic Studies}

The stress-strain graph for the extruded alloy and composite is shown in Figure 3(a) and (b) respectively.

From the nature of the graph it is seen that the alloy exhibits a ductile behaviour but the composite shows a brittle failure. This is possibly due to the incorporation of the $\mathrm{SiC}$ particles that are uniformly distributed in the matrix giving the composite a brittle nature. The fractographic studies of the alloy and composite in the cast condition [Figure 4(a) and 4(b) respectively] confirm the loss of ductility on forming composites as the former shows cup and cone type of fracture relating to ductile nature and the latter shows cleavage facets, voids with inclusions [marked by *] and micro cracks [marked by arrow] which are characteristic features of brittle nature of failure. The deep voids with inclusions are the possible cause of fracture in this case.

The Ultimate Tensile strength [UTS] of the cast, homogenised and extruded alloys and composites are shown in Table $\mathbf{5}$ and plotted in Figure $\mathbf{5}$ for comparison. It is seen that homogenisation increases the UTS for both the alloy and composite resulting possibly from uniformity in the distribution of phases. Extrusion further improves the UTS in the case of alloy though marginally; however for composites a slight decrease has been recorded. The reported results are an average of three sam ples tested in each case.

The fractographs of the tested samples reveals the nature of failure and the effect of homogenisation and/or extrusion on the nature of the sample if any. The fractograph of the homogenised alloy [Figure 6(a)] is very similar to the cast alloy [Figure 6(a)] exhibiting uniform dim-

Table 4. Hardness of alloy and composite under different conditions.

\begin{tabular}{cccc}
\hline System & As Cast & RRA & Extruded \\
\hline Alloy & $50.06 \pm 7.22$ & $71.0 \pm 3$ & $96.6 \pm 3$ \\
Composite & $79.6 \pm 8.35$ & $72.1 \pm 3$ & $101.2 \pm 4$ \\
\hline
\end{tabular}




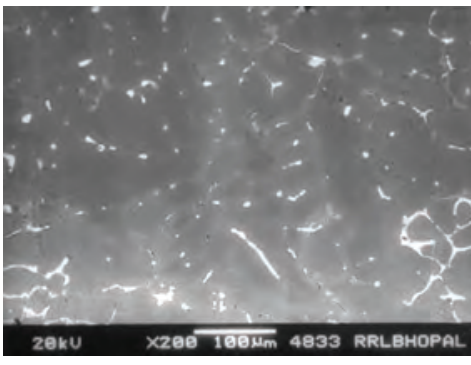

a: Cast Alloy

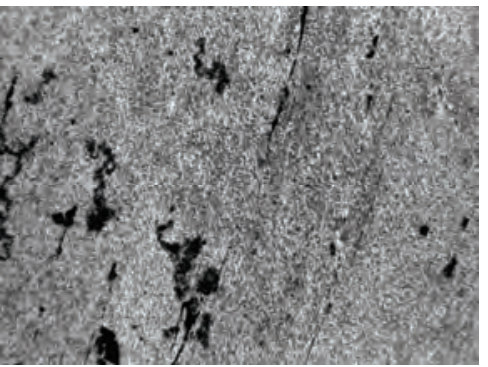

d: Extruded Alloy- longitudinal direction

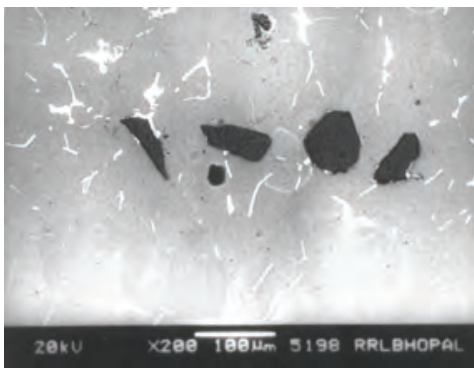

g: Aged Composite -T6

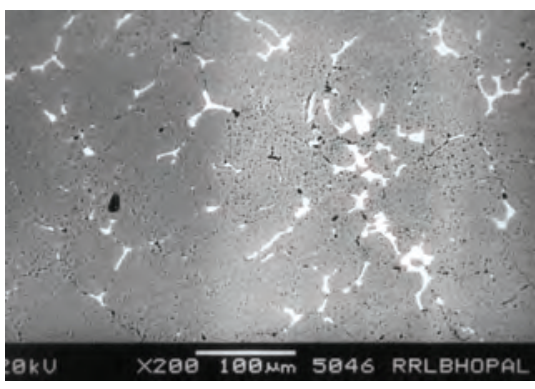

b: Aged Alloy -T6

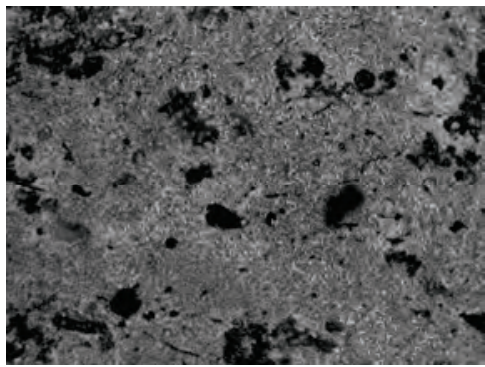

e: Extruded Alloy- transverse direction

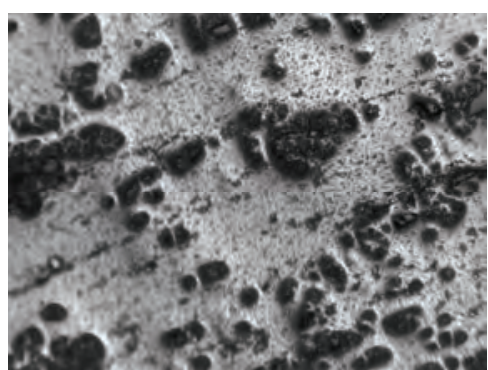

h: Extruded Composite-longitudinal direction

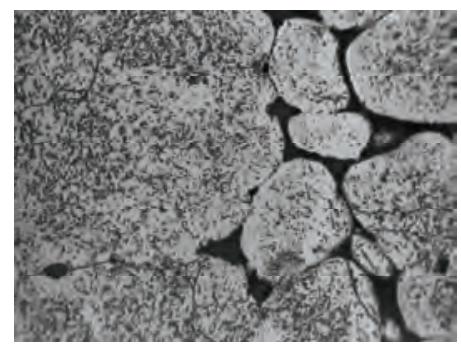

c: Aged Alloy - RRA

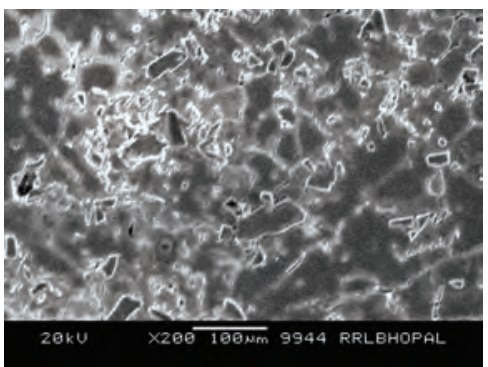

f: Cast Composite

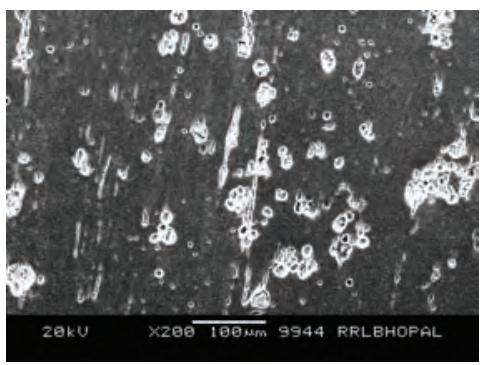

i: Extruded Composite- transverse direction

Figure 2. Microstructure under different conditions.

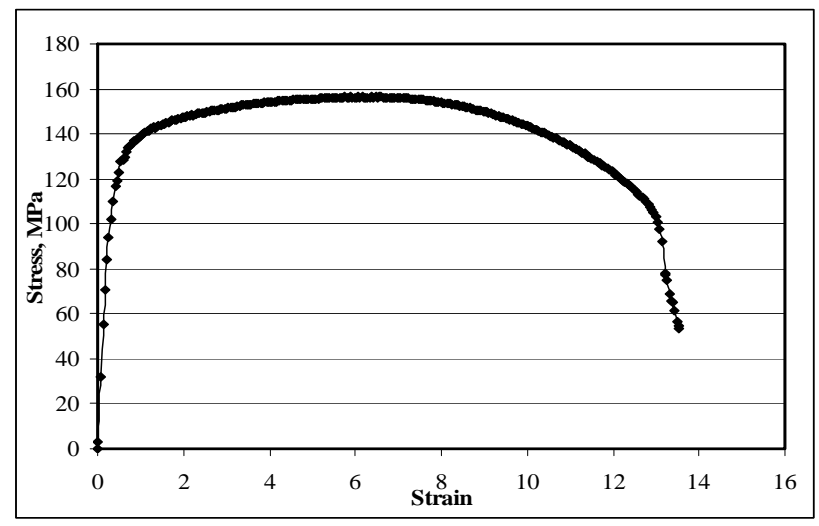

Figure 3. (a) Stress-Strain graph for extruded alloy; (b) Stress-Strain graph for extruded composite.

ples [marked A], with tear ridges indicative of cup and cone type of fracture [marked B] and large number of voids [marked C] indicating ductile fracture [66]. The smooth and fibrous region with proper neck formation at lower

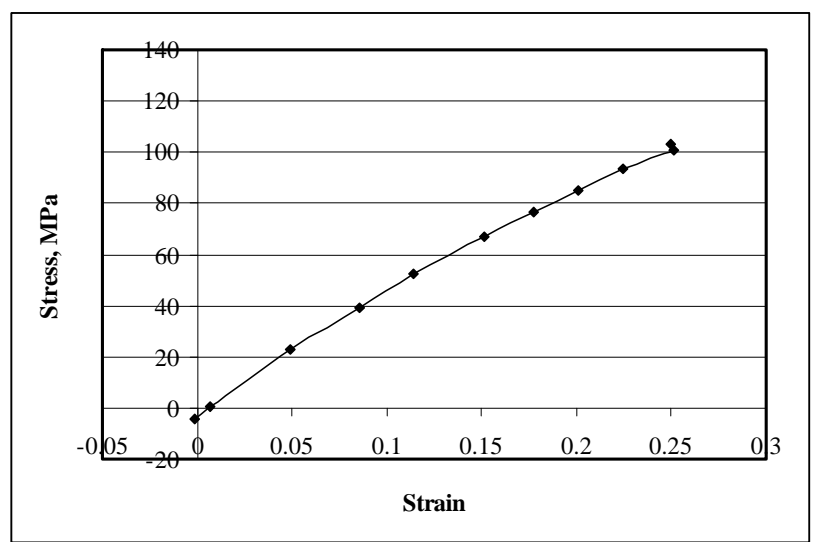

magnifications [Figure 6(b) \& (c)] confirms a pure ductile mode of fracture in both the homogenised and extruded samples. The broken surface of the extruded alloy also exhibit similar structure [Figure 6(d)] with a 
Table 5. UTS of Samples.

\begin{tabular}{cc}
\hline Sample & UTS, MPa \\
\hline Cast Alloy & $87.57 \pm 5.23$ \\
Homogenised alloy & $159.09 \pm 1.88$ \\
Extruded alloy & $165.59 \pm 2.08$ \\
Cast Composite & $81.85 \pm 6.77$ \\
Homogenised Composite & $112.08 \pm 1.48$ \\
Extruded Composite & $103.10 \pm 3.15$
\end{tabular}

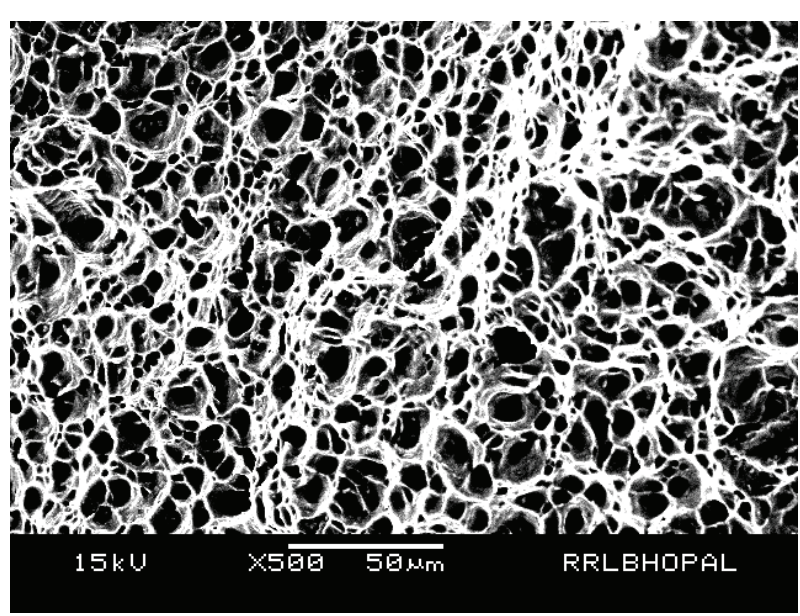

(a)

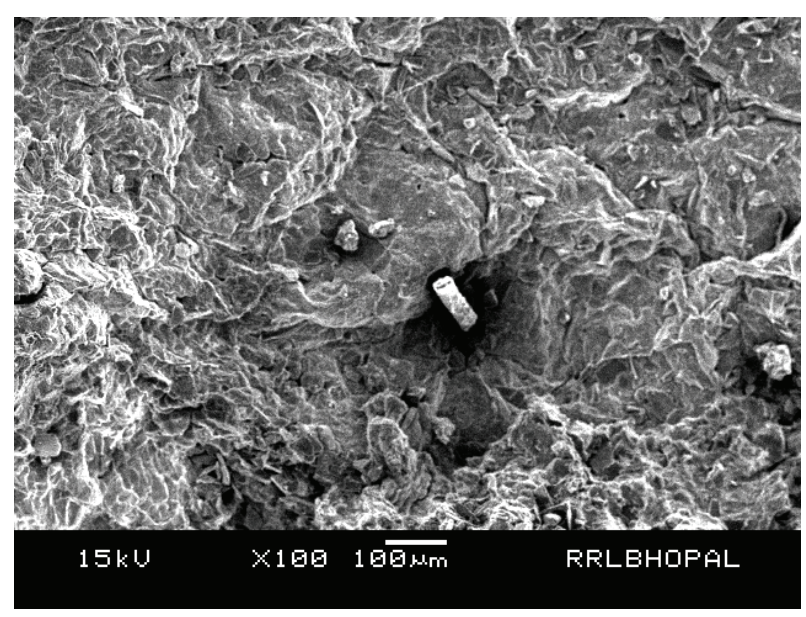

(b)

Figure 4. Fractured surface (a) ductile failure for alloy (b) brittle failure of composites.

high density of equiaxed dimples that is found mainly in ductile materials. Fracture by micro void coalescence [67] is the only mode of fracture to be confirmed. No other physical parameter can be seen in the fractographs of the alloys.

In the case of composites, the fractured surface exhibits a slight modification on homogenisation in which voids are seen along with the cleavage in a very scattered manner [Figure 7(a)] unlike the cast condition where only cleavage facets indicative of brittleness is observed
[Figure 7(b)]. The river patterns on the facets can also be seen [Figure $\mathbf{7 ( b )}$ ] a clear indication of the brittle mode of the fracture in the homogenised samples [68]. Extrusion however increases the number of voids in the fractographs to a considerable extent; certain portions reveal a smoother surface of fracture, revealing numerous equiaxed dimples, suggestive of ductile tensile fracture [Figure 7(c)]; at times incomplete material removal processes are also seen [marked by arrow]. Higher magnification fractographs [Figure 7(d)] shows dimples with an inclusion, which could have been the cause of fracture along with some stretched cleavage facets and majority of shallow dimples. This indicates a mixed mode of fracture i.e. ductile and brittle fracture in the extruded composites.

\subsubsection{Sliding Wear Behaviour and Worn Surface Studies}

Sliding wear tests were carried out on the cast, homogenised and extruded alloy and composite under two speeds of rotation 200 and 750rpm and under three pressures corresponding to 1,3 and $5 \mathrm{MPa}$ and the volume loss against sliding distance plotted. It was found that the alloy in all the conditions seized at $5 \mathrm{MPa}$ pressure at both the speeds of rotation, whereas composites sustained the pressure at the lower speed of rotation. Again, alloys seized even at 3MPa pressure at the higher speed of rotation whereas the composites could sustain the conditions upto the sliding distance tested i.e. $2500 \mathrm{~m}$. Seizure of the material can be understood from the machine stopping and also from the surface being tested which shows material movement; the scanning electron micrographs of seized samples [Figure 8] shows complete overlapping of material and material movement cutting across wear tracks [Figure 8(a)]; the seized material in turn do not show any structure and looks like a lump of mass on the surface adhered to the surface and material from the inner surface are also exposed [Figure 8(b)].

In order to compare the behaviour between the alloy and composite for a particular experimental condition, the volume loss against sliding distance is plotted as in Figure 9, shown below. It is seen that under all the experimental conditions, the composite exhibits lesser volume loss as compared to the alloy through the duration of the test. Moreover, homogenisation of alloy or composite doesnot have any significant bearing in reducing the volume loss and this is probably due to softening of the matrix as a result of homogenisation and volume loss is directly dependant on the hardness and stiffness of the material. The volume loss for composites is significantly lower than the alloy under a particular experimental condition, especially under the same sample condition. Extrusion has a significant effect in decreasing the volume loss for both alloy and compositeand under a pressure of $3 \mathrm{MPa}$ and $200 \mathrm{rpm}$, 


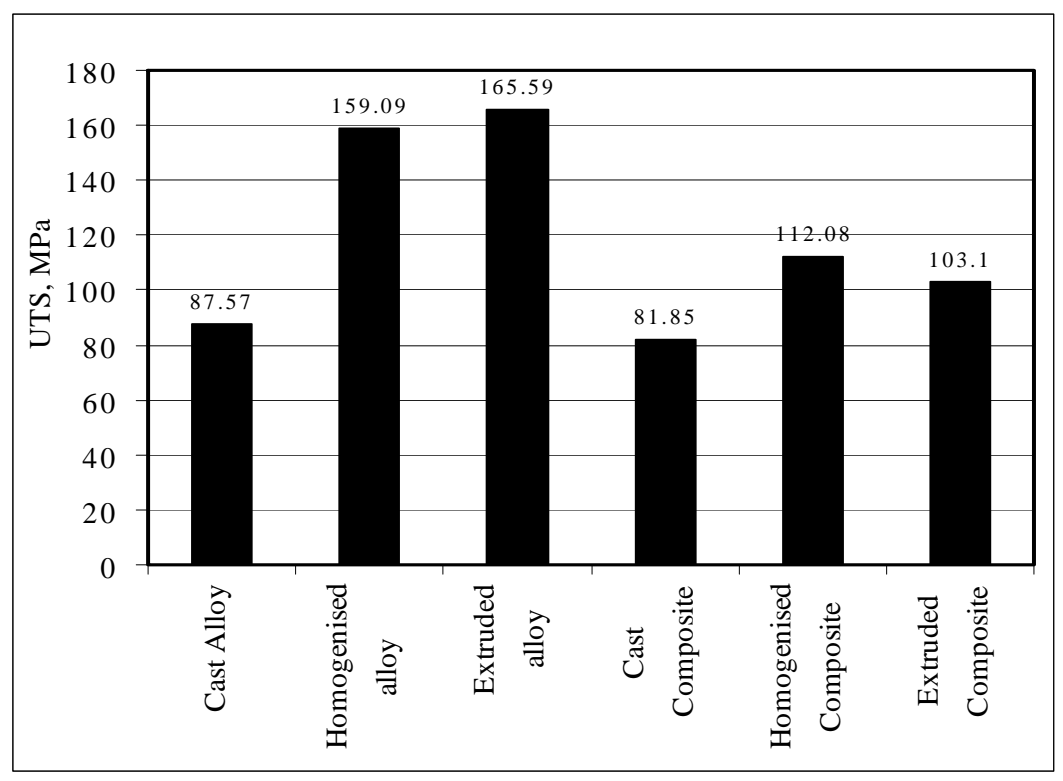

Figure 5. Comparative plot of UTS of the samples.

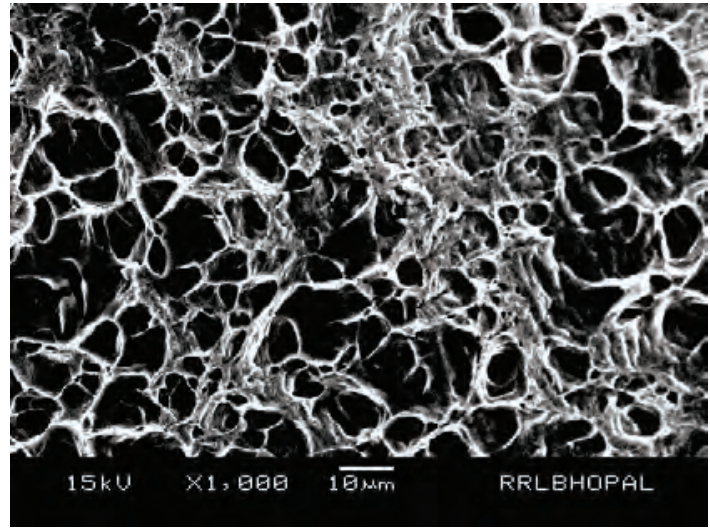

(a)

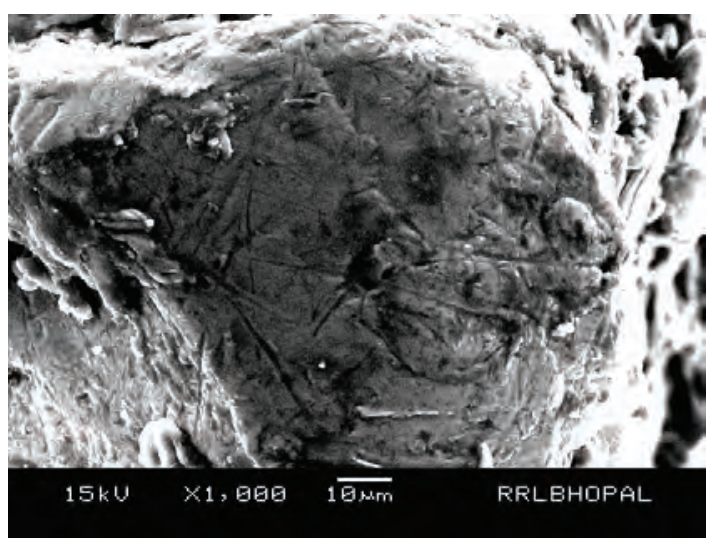

(c)

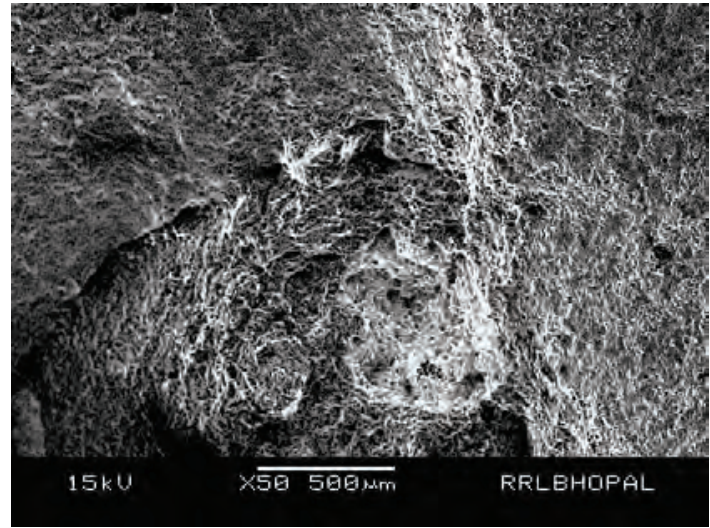

(b)

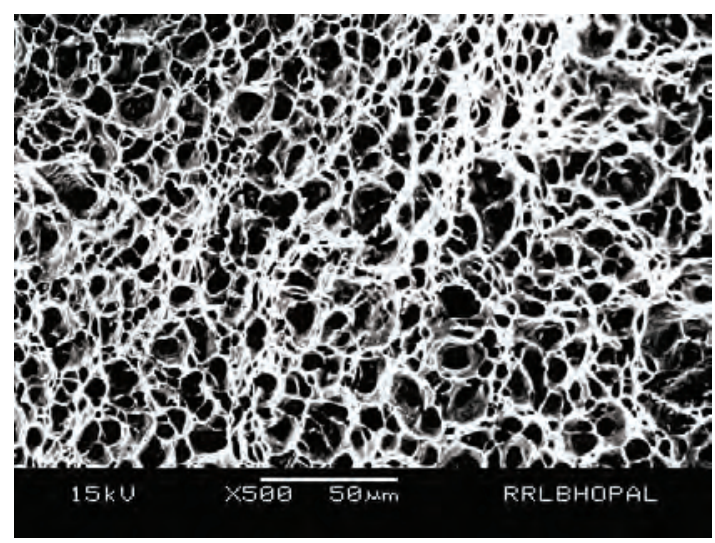

(d)

Figure 6. Fractographs of alloys under different conditions. (a) Homogenised alloy; (b) neck formation at lower magnifications for homogenised and extruded alloys; (d) extruded alloy.

the extruded alloy even exhibits less volume loss i.e. better wear resistance than the cast and homogenised composite. It is interesting to note that higher speeds of rotation results in lesser volume loss which is probably 


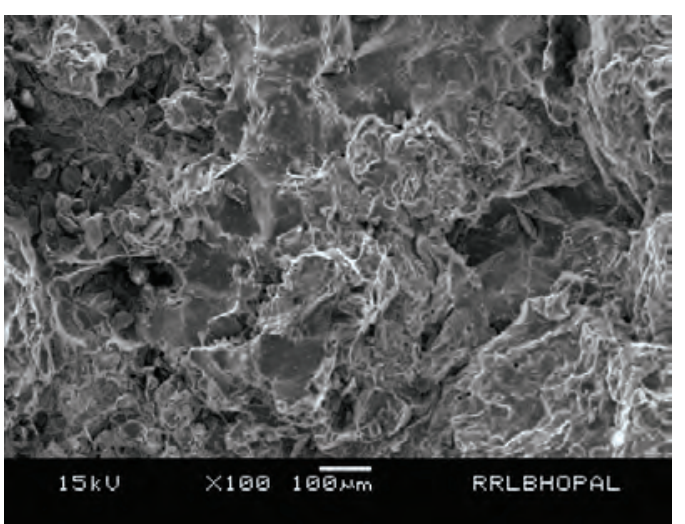

(a)

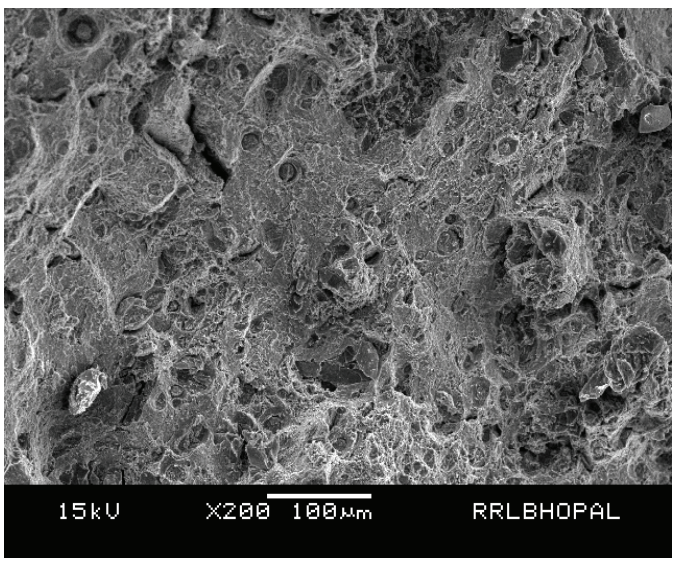

(c)

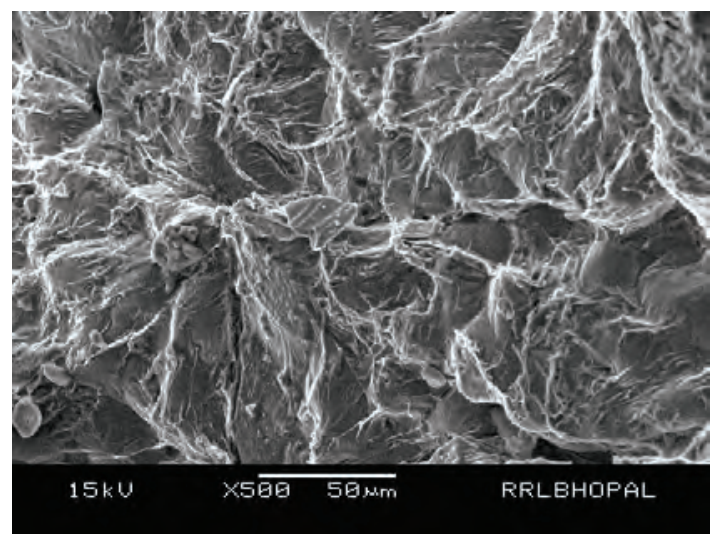

(b)

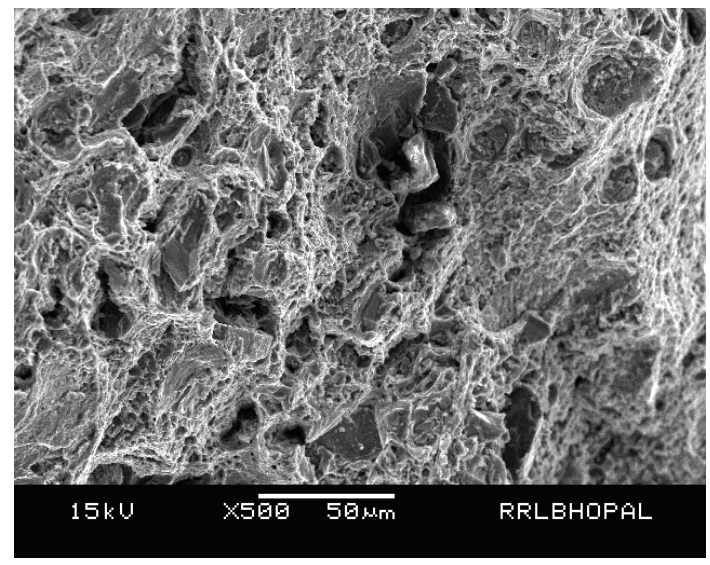

(d)

Figure 7. Fractographs of composites under different conditions.(a) Homogenised composite; (b) homogenised composite showing river patterns on the cleavage facets; (c) extruded composite showing incomplete material removal processes marked by arrow; (d) magnified view of 'c' showing stretched cleavage facets and shallow dimples.

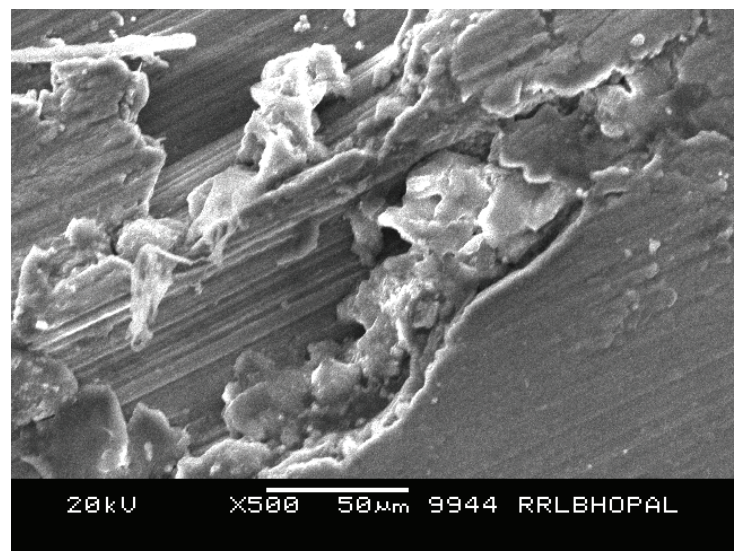

(a)

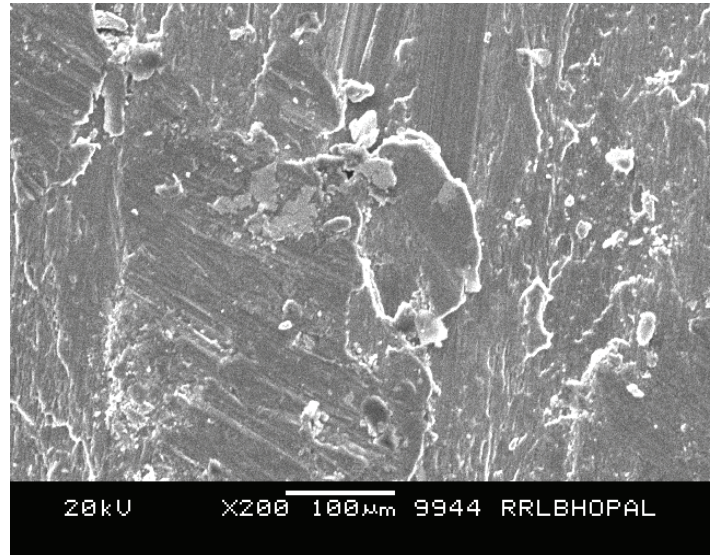

(b)

Figure 8. Micrographs of seized samples.

due to less time that the surfaces get to slide against each other due to the enhanced speed; the material damage is also less in such cases as seen from comparing its worn surfaces at a particular load at different speeds [Figure10]. The effect of load on volume loss is more predominant in the cast condition that in the extruded condition as can be seen on comparing Figures 9(a) and (b).

Unlike alloys, which have seized even under a pressure of $3 \mathrm{MPa}$ at higher speeds of rotation, composites have not experienced seizure under a pressure of $3 \mathrm{MPa}$ 

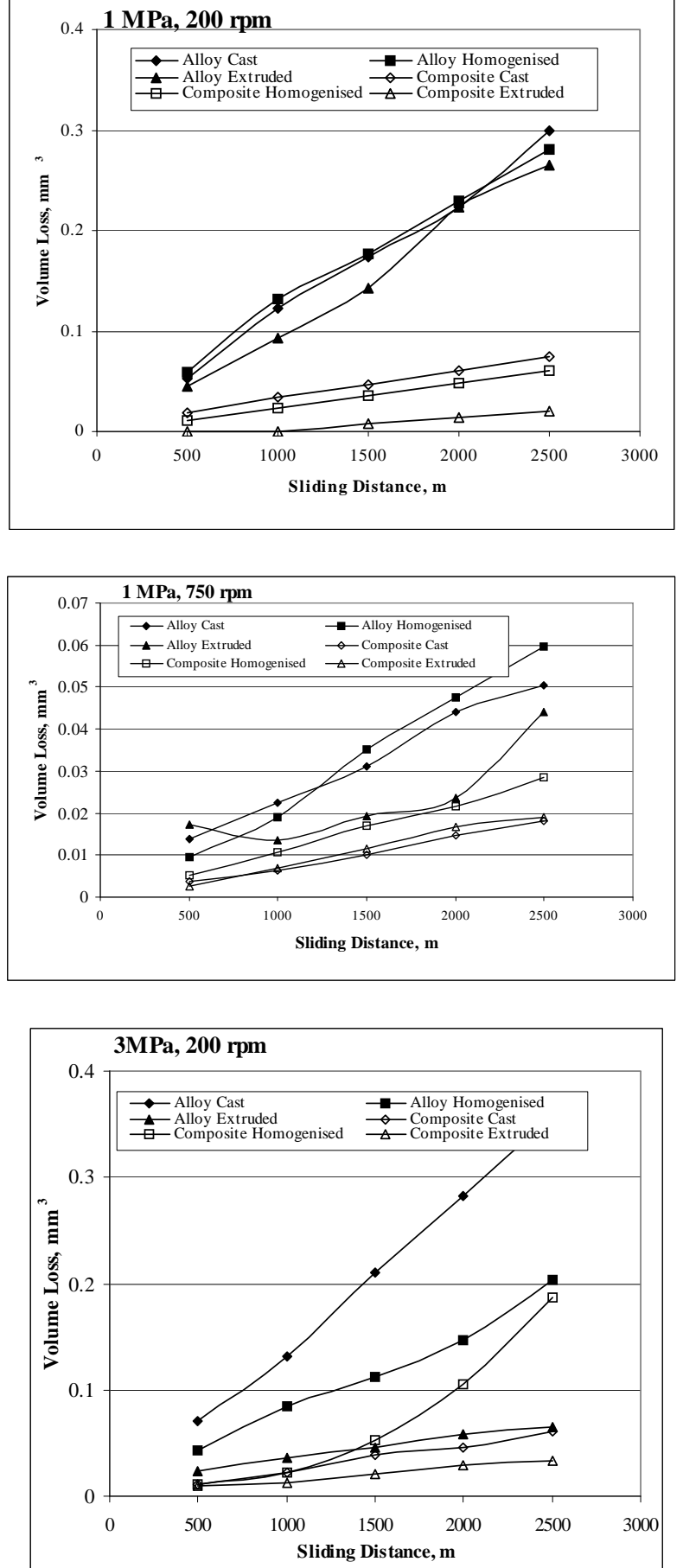

Figure 9. Comparison of volume loss with sliding distance between alloy and composite under different conditions.

under any condition; however the cast and homogenised composites have seized after traversing a minimal distance when the pressure was increased to $5 \mathrm{MPa}$, but even in this condition at both the speeds of rotation they could complete the duration of the test in the extruded condition without any signs of seizure on its worn surface [Figure 11]. The advantage of making composites even
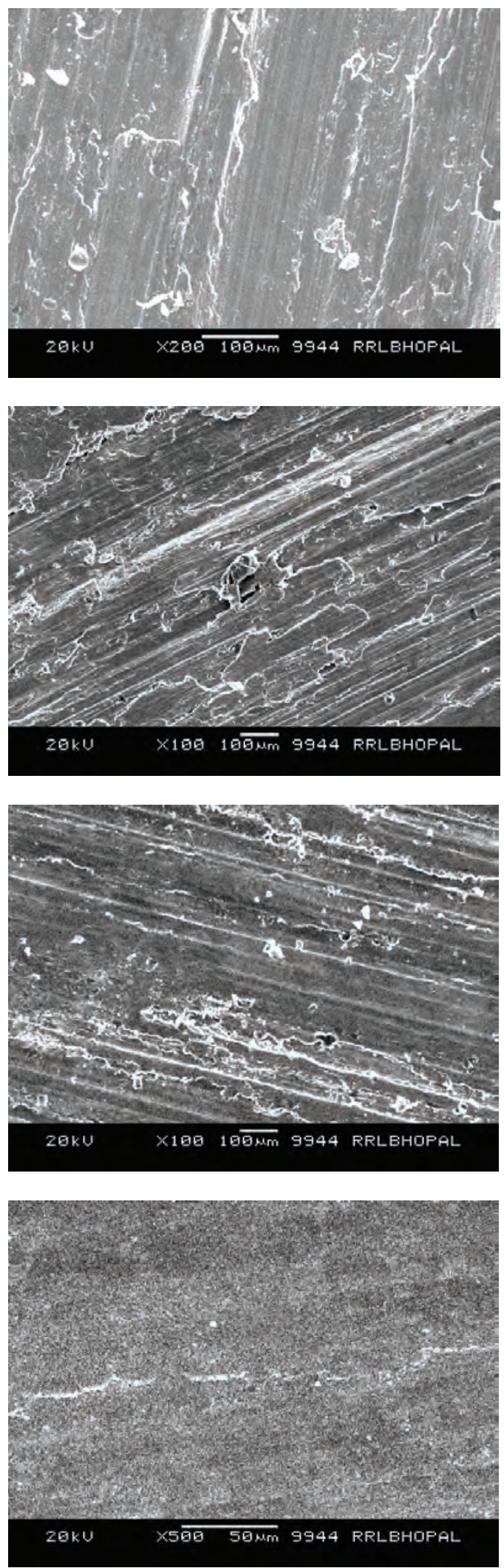

Figure10. Worn surface showing effect of speed at a pressure of $1 \mathrm{MPa}$. (a)alloy at $200 \mathrm{rpm}$; (b) alloy at $750 \mathrm{rpm}$; (c) composite at $200 \mathrm{rpm}$; (d) composite at $750 \mathrm{rpm}$. 

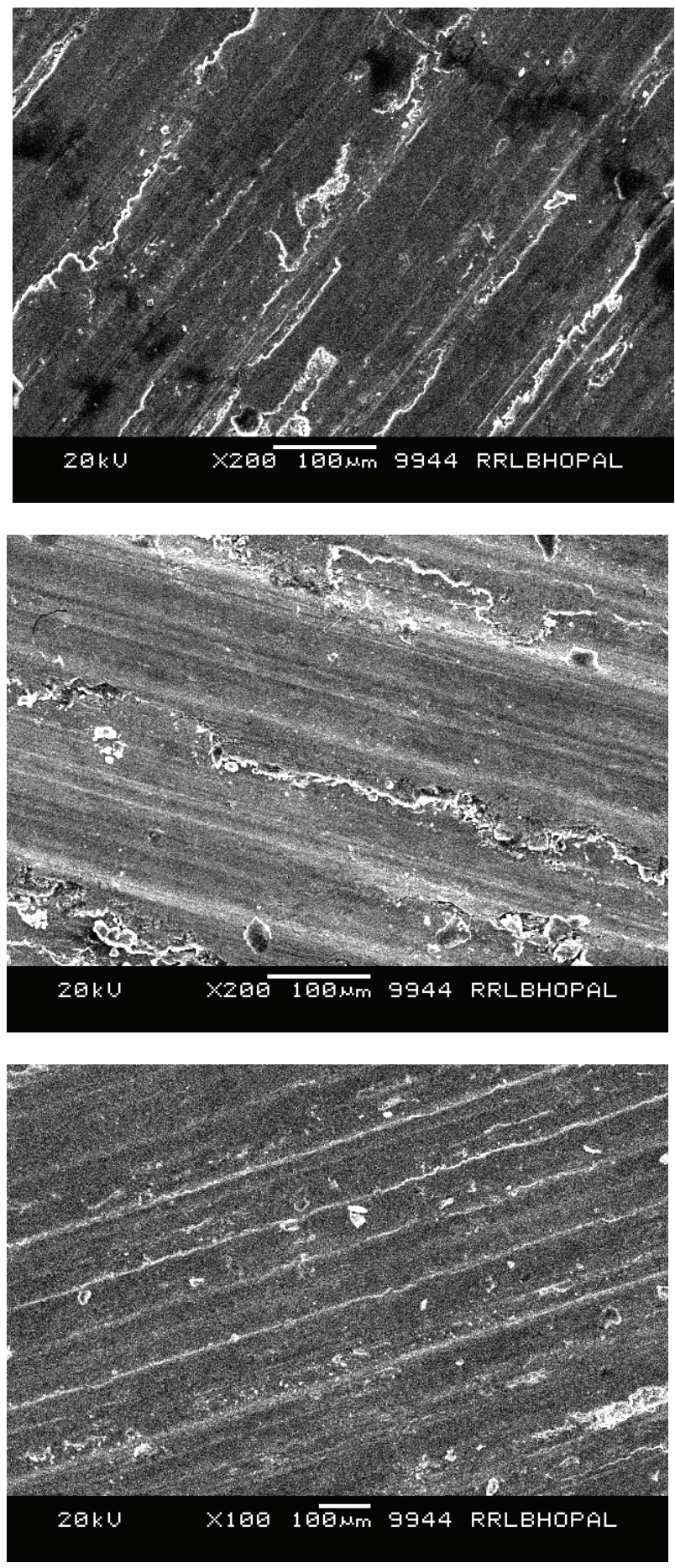

Figure 11. Worn surface of composites at 5MPa pressure. (a) Cast at 200 rpm; (b) Extruded at 200 rpm; (c) Extruded at $750 \mathrm{rpm}$.

from a non conventional wear resistant alloy like the one being discussed is thus established from the above studies and it brings home the point that extrusion improves the sliding wear resistance properties in both the alloy and composite.
In order to compare the effect of extrusion on wear behaviour of composites, the variation for composites under experimental conditions where alloys have seized is plotted in Figure 12. In the Figure, the nature of lines represents the pressure applied like dashed lines represents a pressure of $3 \mathrm{MPa}$ and a filled line a pressure of 5 MPa; again filled symbols represents a sliding speed of $200 \mathrm{rpm}$ and unfilled symbols a speed of rotation of $700 \mathrm{rpm}$; likewise the letters A, D and G is the cast, B, E and $\mathrm{H}$ the homogenised and $\mathrm{C}, \mathrm{F}$ and $\mathrm{I}$ the extruded conditions. From the graph it is seen that the (i) under conditions where the cast and homogenised composites seize at $5 \mathrm{MPa}$ pressure when the speed of rotation is $750 \mathrm{rpm}$ but the extruded composites do not seize (ii) homogenisation or heat treatment softens the material leading to more volume loss under the same experimental conditions even over the cast condition (iii) extruded composites exhibits better wear resistance [as measured from inverse of volume loss] than the cast condition at high pressures; however at lower pressures the cast condition performs marginally better or it can be said that there is no beneficial effect of extrusion when the load is comparatively less, that is to say that extrusion makes the composites more versatile to withstand harsher conditions of wear related damage.

\section{Achievements in a Nutshell}

Al-Zn based composites prepared through different routes like casting, powder and squeeze casting routes have been extensively reported and have been extensively been characterised on a laboratory scale and in very rare cases have these been subjected to secondary processing. However any engineering component from the composites has still not been reported. The main dispersoid that have been investigated are $\mathrm{SiC}$ and $\mathrm{Al}_{2} \mathrm{O}_{3}$. The main findings and best results obtained as a result of forming MMCs are as follows:

- Stronger matrix alloys tend to produce stronger composites although the increase in strength due to reinforcement tends to be lower when higher strength matrix alloy; it was found that composites containing $13 \mu \mathrm{m}$ particles possesses greater toughness than those containing $5 \mu \mathrm{m}$ particles.

- The microstructural studies of composite in the cast condition is dependent on a number of parameters like macro segregation of dispersoid, primary and secondary dendrite spacing, solidification rate, solidification time, dendrite ripening; the cast structure exhibits coarse dendrite grains, however in contrast small non dendritic structure was observed in the aged structure. In both materials the grain size decreases as the strain rate increases.

- The tensile properties of the composite have been investigated by several investigators with a view to assessing its properties vis-à-vis conventional alloy to find 


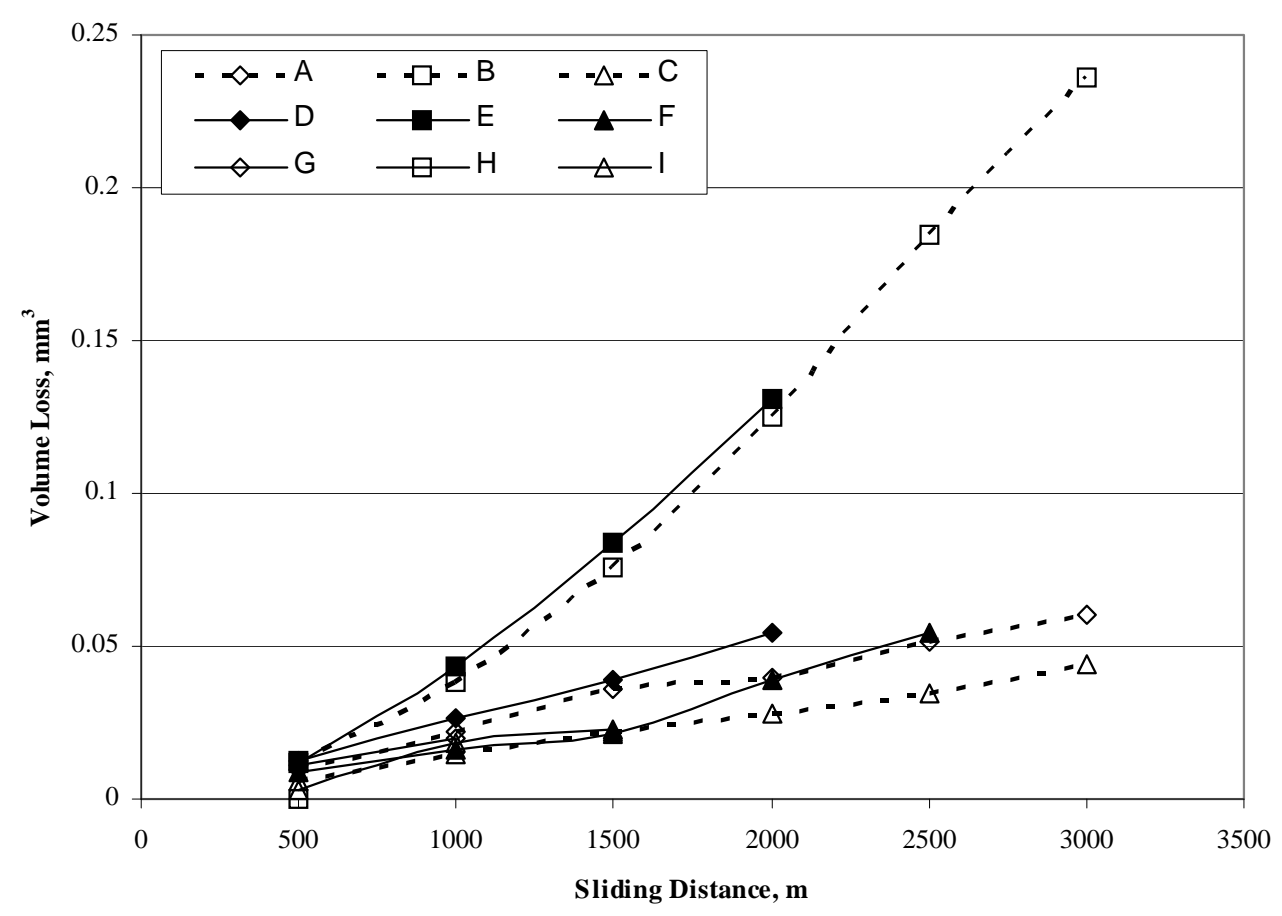

A: Cast, 3MPa, 750 rpm; B: Homogenised, 3MPa, 750 rpm; C: Extruded, 3MPa, 750 rpm

D: Cast, 5MPa, 200 rpm; E: Homogenised, 5MPa, 200 rpm; F: Extruded, 5MPa, 200 rpm

G: Cast, 5MPa, 750 rpm; H: Homogenised, 5MPa, 750 rpm; I: Extruded, 5MPa, 750 rpm

Figure 12. Comparison of wear behaviour under different conditions for composites.

commercial application of the composite. It was found that the properties are dependant on several factors like particle size and volume fraction and there is a peak in the properties attained limiting the size and volume of dispersoids possible for better properties over the monolithic material.

- The best mechanical properties attained in MMCs of this class are made through powder metallurgy routes though this route is not practical for large components and is not economical.

- Strength improvement in a composite may be attributed to good bond strength via enhancement of wetting; also presence of the combination of $\mathrm{Mg}$ and $\mathrm{Zn}$ helps in wetting in this alloy system. This again is dependant on the forming technique and spontaneous infiltration has been found to give the best properties due to an enhancement of wetting between the molten alloy and the reinforcement.

- Effect of alloying elements has an effect even on the properties even after secondary processing of this composite system; the presence of iron produces a slight decrease in strength, elongation and fracture in wrought product. Iron together with manganese may produce a slight increase in strength with limited increase in elongation. Manganese, chromium, molybdenum and zirconium appear to have a strong strengthening effect with corresponding decrease in \% elongation. The effect of silicon addition varies some what depending on $\mathrm{Mg}$ : Zn ratio.

- It has been observed that these alloys are easily worn out. Severe wear at high contact load have been reported. In paraffin oil, the wear rates were approx 1/10 the wear rates under dry conditions; however 7004-T6 showed a lower friction coefficient compared to 2024-T4.

- Creep resistance of the alloys is relatively low, especially for high strength alloys. However, such studies have not been reported for composites of these alloys.

- The role of work hardening characteristics has been shown to be associated with a high dislocation density in the matrix due to the difference in coefficient of thermal expansion between the reinforcement and the matrix.

- The corrosion behaviour of the MMCs was studied by electrochemical measurements to study the effect of the addition of silicon carbide on the corrosion behaviour of the MMC. The corrosion behaviour of the metal matrix composite show that both the cathodic oxygen reduction current density and the anodic dissolution current density are less than those of the alloy. Thus, the addition of $\mathrm{SiC}$ particles increases the corrosion resistance of the MMC.

- Very limited studies have been reported on processing of composites. In a study, the composites were hot rolled to the total rolling reduction of about $94 \%$ at temperatures between $573 \mathrm{~K}$ and $773 \mathrm{~K}$ and at a rolling strain per pass of 0.10 .

- Inspite of the enormous amount of $R \& D$ that has 
gone into Al-based MMCs of this alloy establishing beyond doubt the usefulness of making composites they are yet to produced at competitive rates on a production scale. Until this is done the possibility of making components from the composites inspite of all its advantages will remain a dream.

- Again, before components are thought of some areas needs address. Till now conventional methods/tools as used for the alloys have been used for the purpose but further development and exclusive research on composites per se needs to be addressed to. These include:

- Machining of Composites

- Joining of Composites

- Primary/Secondary Processing

- Equi Channel Angular Pressing

- Composites from Ultrafine Dispersoids

\section{The Stretch, Limit and The Future}

The contributions made towards increasing the state of knowledge in enhancing the physical, mechanical, wear and corrosion resistance has established the efficacy of making composites with better properties than the alloy; the conditions under which the improvements can be best realised have also been established by different researchers throughout the world mainly through laboratory scale studies. It is seen that the properties attained has been stretched to the maximum possible and there is no much scope of further improvement in the properties as the methods and materials used have all been optimised; and since the last decade no further improvement in terms of properties have been recorded. This in a way has put a limiting factor for further improvement.

The next step would be to mass produce these composites adopting the techniques and adhering to parameters that have been established to give the best results and establish feasibility of making composites on a mass scale retaining the improved properties. Until this is done the ultimate aim of making meaningful engineering components from the composites will never be realised.

Together with mass production and making components for the engineering sector, certain aspects specifically for composites need to be addressed like machining, joining, primary and secondary processing.

Further some basic research is also needed like decreasing the size of the dispersoid further to nano- or micro-size and to establish the parameters for uniform distribution; this definitely will further enhance the properties. Also computer simulation and mathematical modeling of composite fabrication is an area where some scattered work has been done; this area would also need to be addressed to that would cut down on actual experimentation and prediction of properties attainable if the nature, shape, size, volume fraction and processing techniques are known.
Some twenty years of research has gone into making composites and with that we till date know so much. Another ten to fifteen years of research in certain areas still not addressed to as mentioned above would help see the composites in the market readily available. It is time instead of reinventing the wheel and treading known paths of property evaluation and improvement that are now more or less guaranteed, the critical issues as mentioned above are taken up for research that would help in taking the laboratory scale composites a step further and a step closer to the engineering sector.

\section{References}

[1] J. E. Hatch, "Aluminium, Properties, Physical Metallurgy and Phase Diagrams,” American Society for Metals, Metals Park, Ohio, 1971.

[2] I .J. Polmear, "Light Metal Age, Metallurgy of the Light Metals,” Edword Arnold Publishers Ltd, London, 1981, p.69.

[3] I. J. Polmear, "Light Metal Age, Metallurgy of the Light Metals,” Edword Arnold Publishers Ltd, London, 1981, p.73.

[4] L. F. Mondolfo, "Grain Refinement in Aluminum Alloyed with Titanium and Boron," Metallurgical and Materials Transactions B, Vol. 2, No. 2, 1971, pp. 465471.

[5] R. C. Dorward, "Precipitate Coarsening during Overaging of Al-Zn-Mg-Cu Alloy," Materials Science and Technology, Vol. 15, No. 10, 1999, pp. 1133-1138.

[6] S. Suresh, T. Christman and Y. Sugimurlan, "Accelerated Ageing in Cast Al Alloy-SiC Particulate Composites,” Scripta Metallurgica, Vol. 23, No.9, 1989, pp. 1599-1602.

[7] J. S. Robinson, S. D. Whelena and R. L. Cudd, "Retrogression and Reaging of 7010 Open Die Forgings," Materials Science and Technology, Vol. 15, No. 6, 1999, pp. 717-724.

[8] A. Deschamps, Y .Brechet and F. Livet, "Influence of Copper Addition on Precipitation Kinetics and Hardening in Al-Zn-Mg alloy," Materials Science and Technology, Vol. 15, No. 99, 1999, pp. 993-1000.

[9] W. S. Lee, W. C. Sue, C. F. Lin and C. J. Wu, "Effect of Aging on High Strain Rate and High Temperature Properties of 7075 Aluminum Alloy,” Materials Science and Technology, Vol. 15, 1999, pp. 1379-1386.

[10] Yi-Lei Wu, F. H. [Sam] Froes, Chenggong Li and Alex Alvarez, "Microalloying of Sc, Ni and $\mathrm{Ce}$ in an Advanced Al-Zn-Mg-Cu Alloy," Metallurgical and Materials Transactions A, Vol. 30A, No. 4, 1999, pp. 10171024.

[11] K. Ural, “A Study of Optimization of Heat Treatment Conditions in Retrogression and Reaging Treatment of 7075-T6 Al alloy,” Journal of Materials Science Letters, Vol. 13, No. 5, 1994, pp. 383-385.

[12] M. Kanno, I. Araki and Q. Cui, "Precipitation Behavior 
of 7000 Alloys during Retrogressional and Reaging Treatment," Materials Science and Technology, Vol. 10, 1994, pp. 599-603.

[13] M. Furukawa, P. B. Berbon, Z. Horita, M. Nemoto, N. K. Tsenev, R. Z. Valiev and T. G. Langdon, "Age Hardening and the Potential for Superplasticity in a Fine Grained Al-Mg-Li-Zr Alloy,” Metallurgical and Materials Transactions A, Vol. 29A, No. 1, 1998, pp. 169177.

[14] J. E. Hatch, "Aluminium Properties and Physical Metallurgy,” American Society for Metals, Metals Park, Ohio, 1984, p. 2.

[15] Y. Huang, F. J. Hummpberys, N. Ridley and Z. C. Wang, "Diffusion Bonding of Hot Rolled 7075 Al alloys," Materials Science and Technology, Vol. 14, 1998, pp. 405410.

[16] J. M. Zhang, M. A. Przystuna and A. J. Luevano, "Characterization of Pore and Constituent Particle Populations in 7050-T7451 Al Plate Alloys," Metallurgical and Materials Transactions A, Vol. 29A, No. 3, 1998, pp. 727-737.

[17] M. G. Zelin and S. Guillard, "Microstructure and Properties of Superplastically Formed Al Alloy 7475 Pans," Materials Science and Technology, Vol. 15, 1999, pp. 309-315.

[18] H. Iwasaki, T. Mori, M. Mabuchi and K. Higashi, "Microstructural Evolution and Plastic Stability during Superplastic Flow in A 7475 Aluminum Alloy,” Materials Science and Technology, Vol. 15, 1999, pp. 180-184.

[19] D. N. Hanlon and W. M. Rainforth, "Some Observations on Cyclic Deformation Structures in the High Strength Commercial Aluminum Alloy AA 7150,” Metallurgical and Materials Transactions A, Vol. 29A, No. 11, 1998, pp. 2727-2736.

[20] Y. N. Kwon and Y. W. C. Hang, “The Effect of Grain Size and Temperature on the Superplastic Behavior of a 7075 Al Alloy,” Metallurgical and Materials Transactions A, Vol. 30A, 1999, pp. 2037-2047.

[21] W. S. Miller and F. J. Humphreys, "Fundamental Relationship between Microstructures and Mechanical Properties of Metal Matrix Composites,” Ed. M. N. Gungar, P. K. Liaw, 517.

[22] Nuesbaum, "New Application for Al. Based MMC," Light Metal Age, Vol. 55, February 1997, p. 54.

[23] R. Asthana, "Reinforced Cast Metals Part I-Solidification Microstructure,” Journal of Material Science, Vol. 33, No. 7, 1998, pp. 1679-1698.

[24] M. S. Zedalis, P. S. Cilman and S. K. Das, "In High Performance Composites for the 1990's,” In: S. D. Das, et. al. Ed., The metallurgy society of AIME, Warrendale PA, 1990, pp. 61-81.

[25] T. J. A. Doel and P. Bowen, "Effect of Particle Size and Matrix Aging Conditions on Toughness of Particle Reinforced Aluminum Based Metal Matrix Composites,” Materials Science and Technology, Vol. 12, No. 7, 1996, pp. 586-594.

[26] E. M. Taleff, G. A. Henshall, T. G. Nieh, D. R. Lesuer and J. Wadsworth, "Warm Temperature Tensile Testing Ductility in Al-Mg Alloys," Metallurgical and Materials Transactions A, Vol. 29A, No. 13, 1998, pp. 1081-1091.

[27] M. J. Hadianford and Y. W. Mai, "In Situ SEM Studies on the Effect of Particulate Reinforcement on Fatigue Crack Growth Mechanism of Aluminum Based Metal Matrix Composites,” Journal of Materials Science, Vol. 30, No. 21, 1995, pp. 5335-5346.

[28] Y. C. Zhou, Z. P. Duan and Q. B. Yang, "Failure of SiC Particulate Reinforced Metal Matrix composites Induced by Laser Thermal Shock,” Metallurgical and Materials Transactions A, Vol. 29A, No. 2, 1998, pp. 685-692.

[29] O. P. Modi, M. Saxena, B. K. Prasad, A. K. Jha, S. Das and A. H. Yegneswaran, "Role of Alloy Matrix and Dispersoid on Corrosion Behaviour of Cast Al alloy Composite,” Corrosion, Vol. 54, No. 2, 1998, pp. 129134.

[30] P. K. Rohatgi, S. Das and R. Asthana, "Science, Technology and Industrial Potential of Cast Metal Ceramic Particle Composites,” in Materials Science and Technology in the future, CSIR, Bhopal, 1985, pp 123-184.

[31] P. K. Rohatgi, R. Asthana and S. Das, "Solidification, Structure and Properties of Cast Metal-ceramic Particle Composites,” International Metals Reviews, Vol. 31, No. 3, 1986, pp. 115-139.

[32] T. S. Srivatsan, "Microstructure, Tensile Properties and Fracture Behaviour of $\mathrm{Al}_{2} \mathrm{O}_{3}$ Particulate Reinforced Aluminium Alloy Metal Matrix Composites,” Journal of Materials Science, Vol. 31, No. 5, 1996, pp. 1375-1388.

[33] S. Sriram, C. Daniels and T. S. Srivatsan, "Influence of $\mathrm{Al}_{2} \mathrm{O}_{3}$ Particulate Reinforcement on Tensile Fracture of an Aluminium Alloy Metal Matrix Composite,” Meatls Materials and Processes, Vol. 17, No. 3, 1995, pp. 183199.

[34] A. M. Gokhale, N. U. Deshpande, D. K. Denzer and J. Liu, "Relationship between Fracture Toughness, Fracture Path, Microstructure of 7050 Aluminium Alloy: Part II. Multiple Micromechanisms-Based Fracture Toughness Model,” Metallurgical and Materials Transactions A, Vol. 29A, No. 4, 1998, pp. 1203-1210.

[35] M. J. Hadianford, J. Healy, Y. W. Mai, "Fracture Characteristics of a Particulate Reinforced Metal Matrix Composite,” Journal of Materials Sciences, Vol. 29, No. 9, 1994, pp. 2321-2327.

[36] T. S. Srivatsan, "Microstructure, Tensile Properties and Fracture Behaviour of Aluminium Alloy 7150," Journal of Materials Science, Vol. 27, No. 17, 1992, pp. 47724781.

[37] A. M. Murphy, S. J. Howard and T. W. Clyne, "Characterisation of Severity of Particle Clustering and Its effect on Fracture of Particulate Metal matrix composites," Material Science and Technology, Vol. 14, 1998, pp. 959-968.

[38] A. J. Shakesheff and G. Purdue, "Designing Metal Matrix Composites to Meet Their Target: Particulate Reinforced Al Alloys for Missile Applications,” $\mathrm{Ma}$ terial Science and Technology, Vol. 14, 1998, pp. 
851-856.

[39] P. D. Pitcher, A. J. Shakesheff and J. D. Lord, "Aluminum Based Metal Matrix Composites for Improved Elevated Temperature Performance,” Material Science and Technology, Vol. 14, 1998, pp. 1015-1023.

[40] C. M. Styles, I. Sinclair, K. Foster and P. J. Gregson, "Work Hardening Effects on SiC Particle Reinforced Aluminum Alloys,” Material Science and Technology, Vol. 14, 1998, pp. 1053-1056.

[41] A. Deschamps, Y. Brechet and F. Livet, "Influence of Copper Addition on Precipitation Kinetics and Hardening in Al-Zn-Mg Alloy,” Materials Science and Technology, Vol. 15, 1999, pp. 993-1000.

[42] W. S. Miller and F. J. Humphreys, "Strengthening Mechanisms in Particulate Metal Matrix Composites," Scripta Metall, Vol. 25, 1991, pp. 33-38.

[43] D. J. Lloyd, "Aspects of Fracture in Particulate Reinforced Metal Matrix Composites,” Acta Metall, Vol. 39, No. 1, 1991, pp. 59-71.

[44] N. J. Hurd, "Fatigue Performance of Alumina Reinforced Meatal Matrix Composites," Materials Science and Technology, Vol. 4, 1988, pp. 513-517.

[45] R. P. Wei, C.-M. Liao and M. Gao, “A Transmission Electron Microscopy Study of Constituent-particleinduced Corrosion in 7075-T6 and 2024-T3 Aluminum Alloys," Metallurgical and Materials Transactions A, Vol. 29A, 1998, pp. 1153-1160.

[46] M. Gao, C. R. Feng and R. P. Wei, "An Analytical Electron Microscopy Study of Constituent Particles in Commercial 7075-T6 and 2024-T3 Alloys," Metallurgical and Materials Transactions A, Vol. 29A, No. 4, 1998, pp. 1145-1151.

[47] D. J. Lloyd and B. Chamberlin, "In Cast Reinforced Composites,” American Society for Metals, Metals Park, 1988, pp. 263-268.

[48] F. M. Hosking, F. F. Portillo, R. Wunderlin and R. Mehrabian, "Composite of Aluminium Alloys: Fabrication and Wear Behaviour,” Journal of Materials Science, Vol. 17, No. 2, 1982, pp. 477-498.

[49] A. Wang and H. J. Rack “Abrasive Wear of Silicon Carbide Particulate and Whisker Reinforced 7091 Aluminum Matrix composites,” Wear, Vol. 146, No. 2, 1991, pp. 337-348.

[50] S. Turenne, Y. Chatigny, D. Simard, S. Caron and J. Masounave, "The Effect of Abrasive Particle Size on the Slurry Erosion Resistance of Particulate Reinforced Aluminium Alloy,” Wear, Vol. 141, No. 1, 1990, pp. 147-158.

[51] L. H. Chen and D. A. Rigney, "Transfer during Unlubricated Sliding Wear of Selected Metal Systems,” Wear, Vol. 105, No. 1, 1985, pp. 47-61.

[52] R. L. Devis, C. Subramaniam and J. M. Yellup, "Abrasive Wear of Aluminium Composites-A Review,” Wear, Vol. 201, No. 2, 1996, pp. 132-144.

[53] B. Venkataraman and G. Sundararajan, "Corellation between the Characteristics of the Mechanically Mixed Layer and Wear Behaviour of Aluminium, Al-7075 alloy and Al-Metal Matrix Composites,” Wear, Vol. 245, No. 1, 2000, pp. 22-38.

[54] A. K. Mukhopadhyay, "On the Nature of Fe Bearing Particles Influencing Hard Anodizing Behavior of AA7075 Extrusion Products,” Metallurgical And Materials Transactions A, Vol. 29A, 1998, pp. 979-987.

[55] C. M. Styles, "Superplastic Forming Behavior of Complex Shapes and Post Forming Mechanical Properties of Aluminum Based SiCp Reinforced Metal Matrix Composites," Materials Science and Technology, Vol. 16, 2000, pp. 759-764.

[56] F. A. Mohamed, "On the Creep Strengthening of SiC Particulate in SiC-Al Composites," Metallurgical and Materials Transactions A, Vol. 28A, No. 12, 1997, pp. 2780-2782.

[57] Y. Li and T. G. Langdon, "An Examination of Creep Data for an Al-Mg Composite," Metallurgical and Materials Transactions A, Vol. 28, No. 5, 1997, pp. 12711273.

[58] K. T. Park, E. J. Lavernia and F. A. Mohamed, "High Temperature Creep of Silicon Carbide Particulate Reinforced Aluminium," Acta Metallurgica et Materialia, Vol. 38, No.11, 1990, pp. 2149-2159.

[59] K. B. Lee and H. Kwon, "Strength of Al-Zn-Mg-Cu Matrix Composite Reinforced with SiC Particles," Metallurgical and Materials Transactions A, Vol. 33A, No. 2, 2002, pp. 455-465.

[60] K. T. Kashyap, C. Ramachandra, C. Dutta and B. Chatterji, "Role of Work Hardening Characteristics of Matrix Alloys in the Strengthening of Metal Matrix Composites,” Bulletin of Materials Science, Vol. 23, No. 1, 2000, pp. 47-49.

[61] Y. L. Cheng, Z. H. Chen, H. L. Wu and H. M. Wang, "The Corrosion Behaviour of the Aluminum Alloy 7075/SiCp Metal Matrix Composite Prepared by Spray Deposition," Materials and Corrosion, Vol. 58, No. 4, 2007, pp. 280-284.

[62] V. Balasubramanian, J. Senthilkumar, M. Balasubramanian, "Optimization of the Corrosion Behavior of AA7075 $\mathrm{Al} / \mathrm{SiC}_{\mathrm{P}}$ and $\mathrm{Al} / \mathrm{Al}_{2} \mathrm{O}_{3}$ Composites Fabricated by Powder Metallurgy," Journal of Reinforced Plastics and Composites, Vol. 27, No. 15, 2008, pp. 1603-1613.

[63] S. Kumar and V. Balasubramanian, "Developing a Mathematical Model to Evaluate Wear Rate of AA7075/ SiCp Powder Metallurgy Composites,” Wear, Vol. 264, No. 11-12, 2008, pp. 1026-1034.

[64] R. K. Bhushan S. Kumar and S. Das, "Optimisation of porosity of 7075 Al Alloy $10 \%$ SiC Composite Produced by Stir Casting Process through Taguchi Method,” International Journal of Materials Engineering Innovation, Vol. 1, No. 1, 2009.

[65] H. Takeo, I. Tsunemichi, K. Toshiro and T. Hiroyuki, "High Strain Rate Superplasticity of the $\mathrm{SiC}_{\mathrm{p}} / 7075 \mathrm{Alu}-$ minum Alloy Composite Made by a Vortex Method," Keikinzoku, Vol. 51, No. 3, 2001, pp. 169-174.

[66] O. C. Wells, "Interpretation of scanning electron microscope fractographs,” John A Fellows, 8th Edition, Metals Handbook, ASM Committee on Fractography by 
electron microscopy, ASM, Vol. 9, 1974, pp. 64-67.

[67] O. C. Wells, "Scanning electron microscope fractographs,” John A Fellows, 8th Edition, Metals Handbook, ASM Committee on Fractography by Electron MicrosCopy, ASM, Vol. 9, 1974, pp. 64-78.
[68] O. C. Wells, "Interpretation of scanning electron microscope fractographs,” John A Fellows, 8th Edition, Metals Handbook, ASM Committee on Fractography by Electron Microscopy, ASM, Vol. 9, 1974, pp. 64-78. 